\title{
Cais Mauá: percepção dos usuários da cidade, diretrizes e o projeto de revitalização para a área
}

\author{
Mauá quayside: users' perception, guidelines, and \\ revitalisation design proposal for the area
}

\section{Fabiana Bugs Antocheviz Antônio Tarcísio da Luz Reis Lucienne Rossi Lopes Limberger}

\section{Resumo}

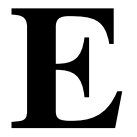

ste artigo tem como objetivo analisar a percepção e a frequência de uso do Cais Mauá, uma área portuária desativada, por parte de três grupos de usuários da cidade de Porto Alegre, identificando os aspectos positivos e negativos percebidos por esses grupos. Ainda, é investigada a relação entre a percepção desses usuários, as diretrizes de intervenção para a orla elaboradas pela Prefeitura de Porto Alegre e pelos pesquisadores, e o projeto de revitalização proposto para esse setor da orla do Guaíba. A coleta de dados consistiu na aplicação de questionários via internet aos três grupos de usuários, nomeadamente arquitetos, não arquitetos com formação universitária e aqueles sem formação universitária. Os resultados possibilitam verificar a importância dessa área urbana no contexto da cidade, confirmando a relevância da percepção dos usuários da cidade na elaboração de diretrizes e no desenvolvimento de projetos de intervenção urbana.

Palavras-chave: Cais Mauá. Percepção dos usuários. Diretrizes de intervenção em orlas. Projeto de revitalização urbana. Área portuária desativada.

Fabiana Bugs Antocheviz Universidade Federal do Rio Grande Porto Alegre - RS - Brasil

Antônio Tarcísio da Luz Reis Universidade Federal do Rio Grande Porto Alegre - RS - Brasil

Lucienne Rossi Lopes Limberger Universidade Federal de Santa Maria Santa Maria - RS - Brasil

Recebido em 23/08/16 Aceito em 12/11/16

\section{Abstract}

This paper aims to analyze the perception and frequency of use of the inactive port area of Mauá Quayside, by three groups of Porto Alegre City users, the positive and negative aspects perceived by users being identified. Moreover, the relationship among city users' perception, the waterfront guidelines developed by the City Council of Porto Alegre and those proposed by the researches, and the revitalization design proposal for this sector of Guaiba Waterfront are investigated. Data gathering means include the application of questionnaires via the internet to the three groups of users, namely architects, non-architects college graduates, and non-college graduates. The results make it possible to verify the importance of this urban area in the context of the city, confirming the relevance of city users' perception to produce guidelines and to develop urban intervention projects.

Keywords: Mauá quayside. Users' perception. Waterfront guidelines. Revitalization design proposal. Inactive harbour area. 


\section{Introdução}

Áreas portuárias de várias cidades têm sido desativadas e segregadas das áreas urbanas próximas, com proibição ou limitação do acesso e uso público de tais áreas (ROBERTSON, 1995). Como consequência, a revitalização de áreas portuárias desativadas tem sido adotada como uma das estratégias de regeneração urbana em cidades de diversos países, tais como Baltimore, Boston, San Francisco, Toronto, Londres, Amsterdã, Lisboa, Barcelona, Tóquio, Hong Kong e Sydney (MACDONALD, 2008; DONOFRIO, 2007). Em cidades como Boston, Vancouver, Toronto e Buenos Aires (Figura 1), o uso misto das edificações e a preservação de edifícios históricos fazem parte das diretrizes de revitalização das antigas áreas portuárias (DONOFRIO, 2007; TELLA, 2012).

A revitalização da área portuária de Baltimore (Estados Unidos) (Figura 2) também preservou edifícios de valor histórico, além de promover o uso público da área e criar passarelas de pedestres interligando a área do porto e o restante da cidade (DEL RIO, 2001). Por sua vez, a revitalização da área portuária de Bilbao, Espanha, teve como objetivo a alteração da imagem do local, antes visto como área industrial e agora considerado um lugar turístico da cidade (MARSHALL, 2001).

No Brasil, a revitalização de áreas portuárias desativadas tem como projeto pioneiro o da Estação das Docas em Belém do Pará (Figura 3) (SILVA; MONIÉ, 2014). A requalificação da área incluiu a implantação de espaços para atividades culturais e de lazer, restaurantes, lojas e outras atividades comerciais e de serviço nos antigos armazéns do porto, vindo a atuar como um local de atração de turistas, além de residentes em Belém (TOMAZI, 2011). Outro projeto de grande destaque é o do "Porto Maravilha", no Rio de Janeiro, que utiliza um projeto âncora como atrator, o Museu do Amanhã (Figura 4), projeto do arquiteto espanhol Santiago Calatrava (PASSOS, 2013). Segundo Silva e Monié (2014) a requalificação da área portuária visa manter a identidade cultural existente, na tentativa de evitar conflitos com a população local e visando a produção e a difusão de conhecimento sobre a memória da região. Contudo, nesses dois processos de revitalização não foram coletadas e consideradas informações acerca das percepções das populações locais.

Figura 1 - Revitalização do Porto Madero (Argentina)

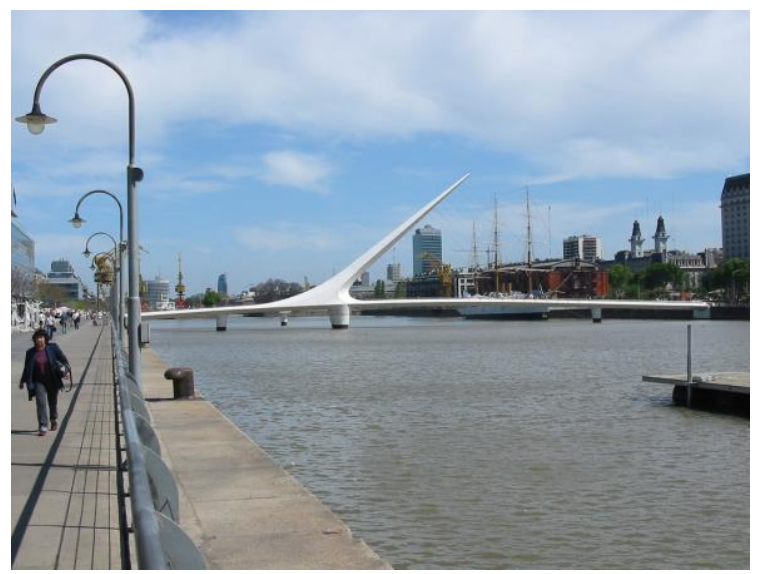

200 Antocheviz, F. B.; Reis, A. T. da L.; Limberger, L. R. L. 
Figura 2 - Revitalização da área portuária de Baltimore (Estados Unidos)

Fonte: Huffpost (2017).

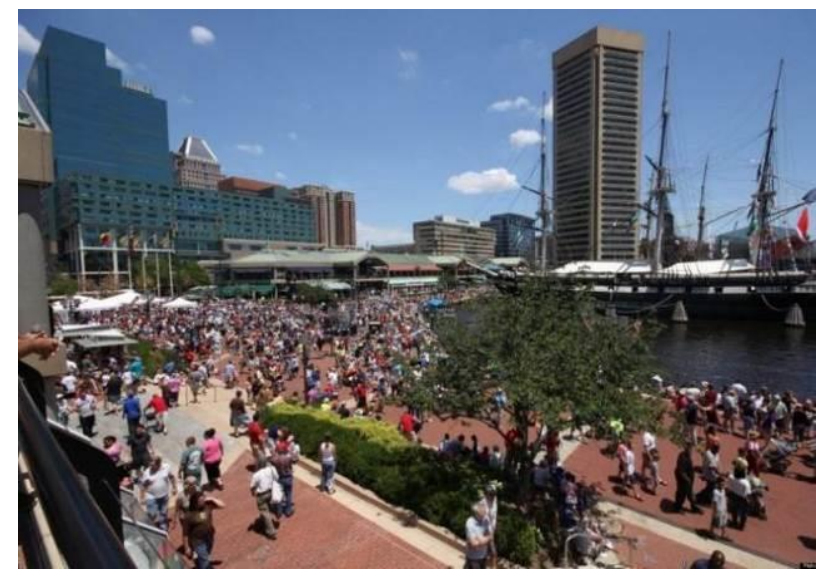

Figura 3 - Estação das Docas em Belém do Pará

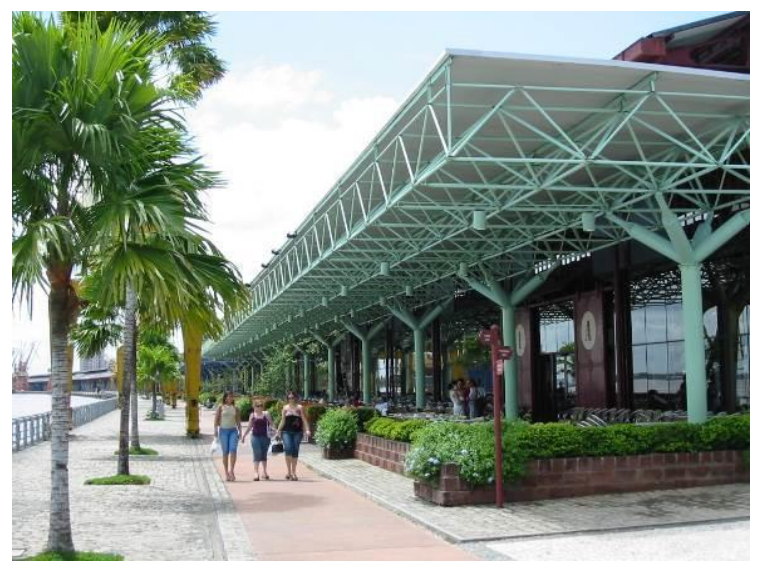

Figura 4 - Porto Maravilha no Rio de Janeiro

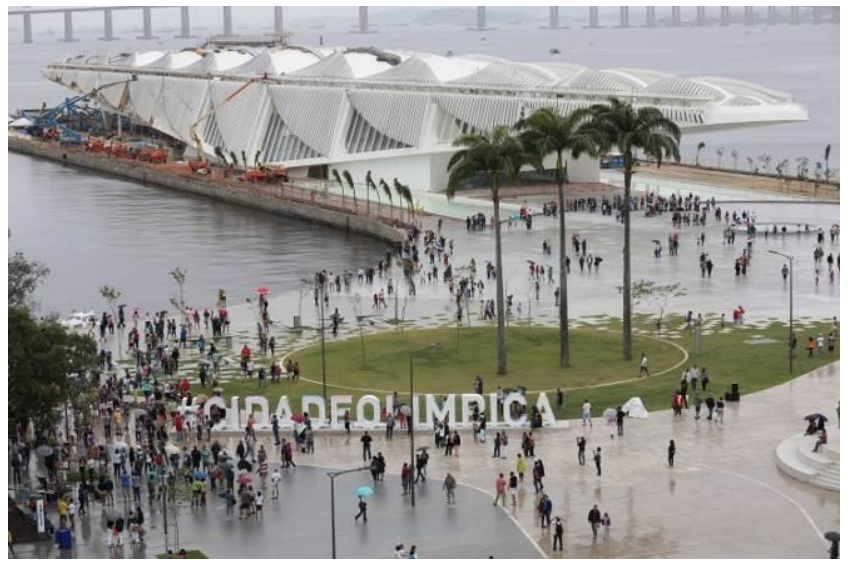

Fonte: Estação das Docas (2017).

A relevância da percepção de vários grupos de usuários do espaço urbano é evidenciada em diversos estudos que enfatizam que as avaliações que envolvem o espaço urbano ou edificações deveriam ser realizadas por arquitetos e pessoas leigas, sem formação universitária e com formação em outras áreas profissionais, para que se possam verificar as percepções dos profissionais que projetam os espaços, assim como dos distintos usuários do espaço urbano (PURCELL; NASAR, 1992; BROWN; GIFFORD, 2001). Adicionalmente, vários estudos sobre a conexão 
entre orlas e áreas urbanas salientam a relevância de se considerar a percepção dos usuários da cidade a respeito de tais orlas (DONOFRIO, 2007; TELLA, 2012). Nesse sentido, as experiências bem sucedidas de revitalização de áreas portuárias desativadas mostram a importância de se considerar a percepção dos usuários da cidade a respeito de tais áreas, além do envolvimento dos governos locais e do setor privado (DEL RIO, 2001). Os usuários, por sua vez, podem possuir diferentes características. Assim, enquanto alguns estudos revelam o efeito da formação acadêmica nas avaliações estéticas, por exemplo, entre as avaliações de arquitetos e leigos (FAWCETT et al., 2008), outros (REIS et al., 2011) apresentam evidências de que quando a ideia de ordem é claramente percebida e se é estimulado visualmente a resposta estética é positiva, independentemente do tipo e do nível de formação acadêmica. Logo, existem contradições acerca do impacto gerado pela formação acadêmica nas avaliações estéticas.

Por sua vez, o declínio de zonas portuárias atinge um dos maiores símbolos da cidade de Porto Alegre, a área da orla onde se situa o Cais Mauá (CASTELLO, 1985). A área portuária do Cais Mauá em Porto Alegre, desativada desde 2005, vem sofrendo um processo de segregação do restante da cidade desde a construção de uma série de armazéns em fita de uso restrito na área do cais entre os anos de 1911 e 1921 (Figuras 5 e 6). Após as enchentes de 1941 e 1967, foi construído o muro da Mauá em 1974 com o objetivo de funcionar como um sistema de proteção contra inundações, o que aumentou a barreira física e visual entre o centro da cidade e as áreas na orla do Lago Guaíba (PREFEITURA..., 2010). Embora diretrizes de intervenção para a orla tenham sido elaboradas pela Prefeitura de Porto Alegre e um projeto de revitalização tenha sido proposto para a área do Cais Mauá, não existem evidências conclusivas que mostrem o quão importantes são o Cais Mauá e a orla do Guaíba para os usuários da cidade e quais são as atividades mais valorizadas pelas pessoas para essa área. Ainda, não existem estudos sobre as relações entre as percepções dos distintos usuários da orla, as diretrizes adotadas pela Prefeitura e o recente projeto de revitalização para a área do Cais Mauá.

Portanto, é necessário aprofundar o conhecimento a respeito do nível de concordância entre as percepções dos usuários da cidade com diferentes níveis e tipos de formação acadêmica, as decisões tomadas pelo governo local e as diretrizes de projeto adotadas pelos arquitetos em relação ao Cais Mauá. Portanto, este artigo tem como objetivo analisar a percepção e a frequência de uso do Cais Mauá por parte de três grupos de usuários da cidade de Porto Alegre, com distintos níveis e tipos de formação acadêmica, identificando os aspectos positivos e negativos percebidos por esses grupos. Ainda, é investigada a relação entre a percepção desses usuários, as diretrizes de intervenção para a orla elaboradas pela Prefeitura de Porto Alegre e pelos pesquisadores, e o projeto de revitalização proposto para o setor da orla do Guaíba constituído pelo Cais Mauá.

\section{Método}

A cidade de Porto Alegre tem setenta quilômetros de orla divididos em dezenove setores de acordo com suas diferentes características (PREFEITURA..., 2010). Conforme problemas e potencialidades diagnosticados, a Prefeitura de Porto Alegre definiu diretrizes gerais de preservação e intervenção para cada um desses setores. Essas diretrizes também estão baseadas em alguns projetos de revitalização de orlas em cidades com características semelhantes às de Porto Alegre, tal como o projeto desenvolvido para o Porto Madero em Buenos Aires (TELLA, 2012; TUTIKIAN, 2008).

As diretrizes consideradas para estudo dizem respeito à área de orla denominada de seção quatro ou Cais Mauá, próxima ao centro de Porto Alegre (Figura 5), que apresenta o maior número de barreiras visuais e físicas com o restante da cidade (PREFEITURA..., 2010), constituída pelos seguintes setores (Figuras 5 e 6 ):

(a) Setor 1 - Docas (área entre a Rodoviária e o Mercado Público, onde se localizam as docas do porto antigo, galpões usados como depósito, o antigo edifício do frigorífico desativado e a Praça Edgar Schneider);

(b) Setor 2 - Armazéns (área entre o Mercado Público e a Praça Brigadeiro Sampaio, paralela à Avenida Mauá); e

(c) Setor 3-Gasômetro (área entre a Marina Pública e o Centro Cultural Usina do Gasômetro).

Visto que as outras diretrizes são muito abrangentes ou pouco claras, apenas seis diretrizes da Prefeitura para a orla (de um total de 14) foram avaliadas pelos respondentes, nomeadamente:

(a) incentivar o uso dos setores com a criação de uma área de circulação de pedestres no Guaíba;

(b) proporcionar a reintegração da população com a orla, por meio de atividades relacionadas com o uso da água; 
(c) proporcionar a valorização e a preservação dos espaços abertos, privilegiando a vegetação e a paisagem;

(d) otimizar a implantação de atividades que explorem a conexão visual com o Guaíba (ex.: bares e restaurantes);

(e) ser de livre acesso à população, com usos públicos; e

(f) reciclar o uso dos armazéns preservando as edificações existentes, favorecendo a cultura e o turismo.

Além dessas seis diretrizes da Prefeitura para a orla, os respondentes avaliaram quatro diretrizes propostas pelos próprios pesquisadores (autores deste artigo), com o propósito de investigar aspectos importantes que não foram especificamente mencionados nas diretrizes elaboradas pela Prefeitura, mas que estão relacionados ao projeto de revitalização da área elaborado por um escritório de arquitetura, especificamente:

(a) proporcionar o uso residencial em partes dos setores;

(b) proporcionar o uso para escritórios em partes dos setores;

(c) permitir novas construções com altura superior à dos armazéns; e

(d) incentivar a preservação das edificações existentes na área, sem novas construções.

O projeto de revitalização do Cais Mauá faz parte do processo de qualificação do centro de Porto Alegre, que envolve acesso à população, mobilidade urbana, turismo, revitalização de espaços abertos e de edificações que fazem parte do patrimônio histórico. Além de manter os armazéns, o projeto inclui novos edifícios comerciais, um shopping center, a implementação de atividades culturais e de lazer e atrações turísticas (MELENDEZ, 2011; B720..., 2011; BLOG..., 2011; PREFEITURA..., 2012).

O projeto também é dividido nos mesmos três setores (Figuras 5 e 6):

(a) Setor 1 - Docas;

(b) Setor 2 - Armazéns; e

(c) Setor 3-Gasômetro.

Especificamente, para revitalizar o Setor 1 Docas são propostos três torres comerciais, um centro comercial no antigo frigorífico desativado e uma grande área de estacionamento (Figura 7). Conforme o escritório de arquitetura responsável pelo projeto, o Setor 2 - Armazéns é considerado a área mais limitada do trabalho, visto que os armazéns são considerados de valor histórico e arquitetônico e são protegidos pela Equipe do Patrimônio Histórico e Cultural (EPAHC), instituição vinculada à Prefeitura de Porto Alegre responsável pela preservação do patrimônio cultural. Nesse setor são propostos espaços para atividades de lazer, gastronomia, educação e artesanato (Figura 7). Esse setor é considerado pelos arquitetos como estratégico para intervenção, o que possibilita uma série de conexões entre a orla e o tecido urbano adjacente e a consolidação de um ponto intermodal de transporte público, próximo à Praça Revolução Farroupilha (Figuras 5 e 6).

O Setor 3 - Gasômetro enfatiza a presença de atividades comerciais, de maneira a não obstruir a relação entre a orla e as áreas urbanas adjacentes (Figuras 5 e 6). Logo, essas atividades serão abrigadas em um edifício baixo integrado ao meio ambiente e conectado ao Centro Cultural Usina do Gasômetro, visando fortalecer a zona portuária da cidade. Uma nova conexão entre esse setor e a Praça Brigadeiro Sampaio será criada pelo rebaixamento da Avenida João Goulart e pela criação de uma passarela de pedestres sobre essa avenida.

Inicialmente, foi aplicado um estudo piloto no próprio Cais Mauá, com dez participantes, para testar a compreensão das questões e o tempo requerido para responder o questionário. Após a aplicação do estudo piloto, foram realizados os ajustes necessários e os questionários foram disponibilizados via internet, no programa LimeSurvey, para os respondentes mediante um link divulgado nas redes sociais, e-mails e grupos de discussão a respeito da revitalização do Cais Mauá. A opção pela coleta de dados via internet deu-se em função das dificuldades em encontrar, durante o estudo piloto, pessoas no Cais Mauá que estivessem dispostas e disponíveis para responder o questionário. $\mathrm{O}$ uso da internet também possibilitou a obtenção de um maior número de respondentes em um menor espaço de tempo em relação à aplicação in loco, além de eliminar a necessidade do encontro presencial para aplicação do questionário. Contudo, muitos respondentes não chegaram a completar mais da metade do questionário, mesmo com a possibilidade de salvar o questionário e voltar a respondê-lo e finalizá-lo em outro momento. Uma das possíveis causas do número de questionários incompletos foi a inexistência da opção "pular a questão" bem como da opção "voltar" para consultar questões anteriores.

Como critério para responder o questionário, o respondente deveria residir ou trabalhar em Porto Alegre há, no mínimo, um ano, tendo uma relação 
de familiaridade com a cidade. Os respondentes foram agrupados em três grupos conforme os objetivos do trabalho: arquitetos, não arquitetos com formação universitária (em cursos que não tratassem de estética), e pessoas que não tivessem concluído ou iniciado curso universitário. O questionário foi constituído de perguntas fechadas simples a respeito da frequência com que os setores são utilizados e os aspectos positivos e negativos de cada um dos três setores do Cais Mauá. Ainda, foram incluídas perguntas de escolha simples relacionadas aos níveis de satisfação dos respondentes no tocante ao projeto de revitalização da área. As perguntas foram baseadas em fotografias da área atual (Figura 6), o que permitiu simular um ambiente real (SANOFF, 1991), e imagens do projeto divulgadas pela mídia (Figura 7). Os questionários foram aplicados entre os dias 25 de dezembro de 2012 e 7 de janeiro de 2013. A amostra final da aplicação via internet ficou condicionada ao tempo em que o questionário fica disponível conforme as conveniências da pesquisa e a amostra mínima aceitável conforme os objetivos da pesquisa.

Figura 5 - Cais Mauá e sua divisão em três setores - orla junto ao Centro de Porto Alegre

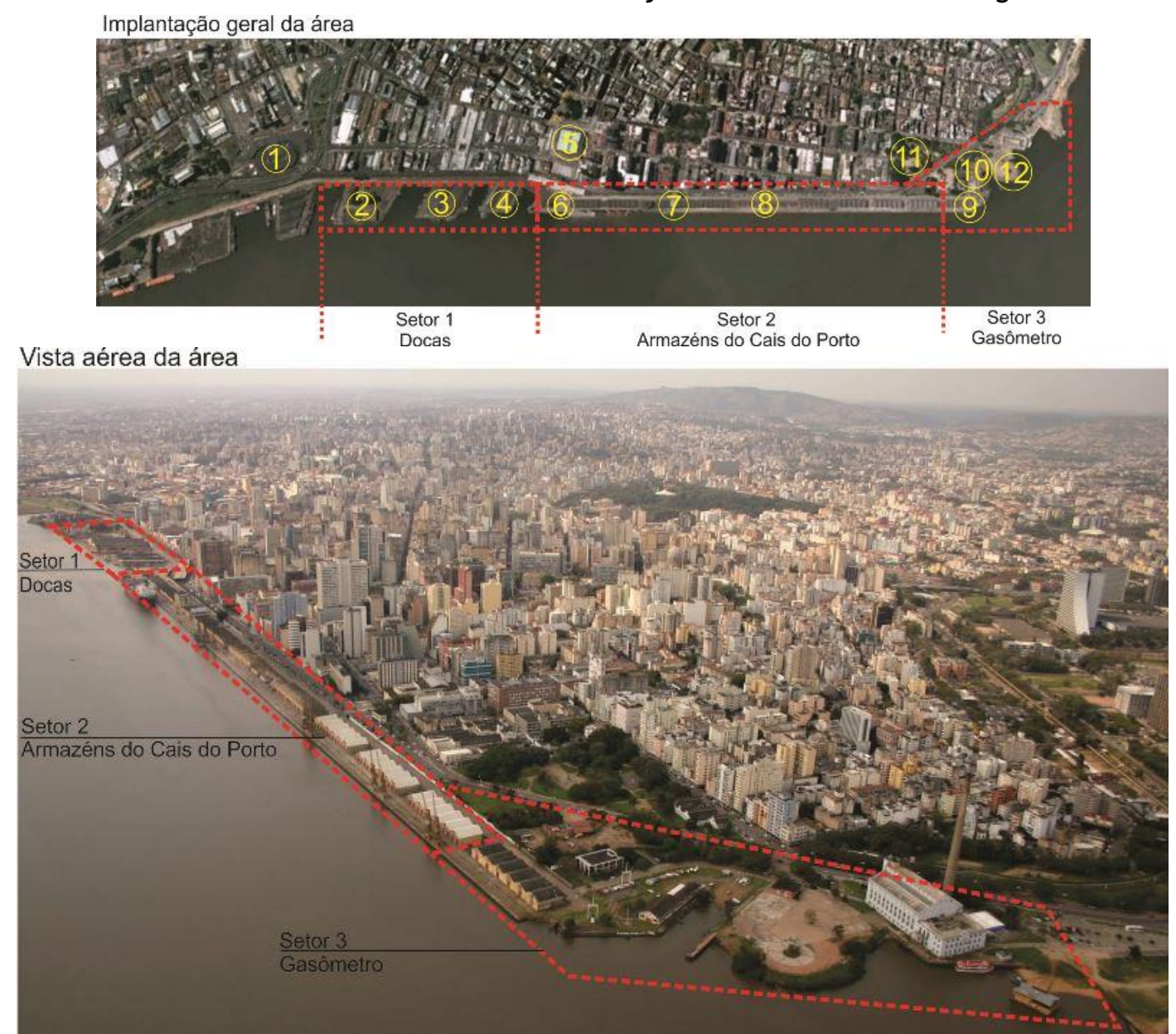

Fonte: adaptado pelos autores a partir de imagens de Porto Alegre (GOOGLE..., 2012) e da antiga Secretaria de Planejamento Municipal (SPM) da Prefeitura de Porto Alegre (2012).

Nota: Legenda:

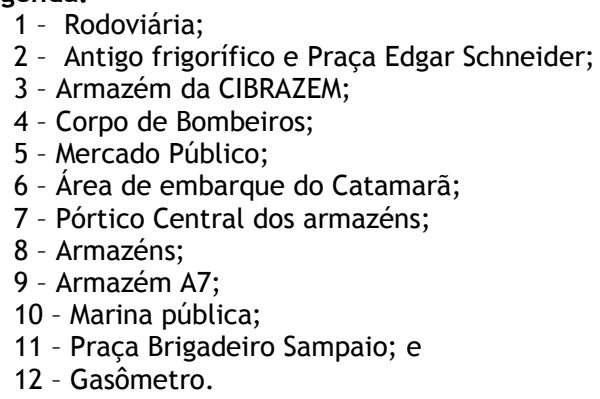

204 Antocheviz, F. B.; Reis, A. T. da L.; Limberger, L. R. L. 
Figura 6 - Cais Mauá e vista dos três setores
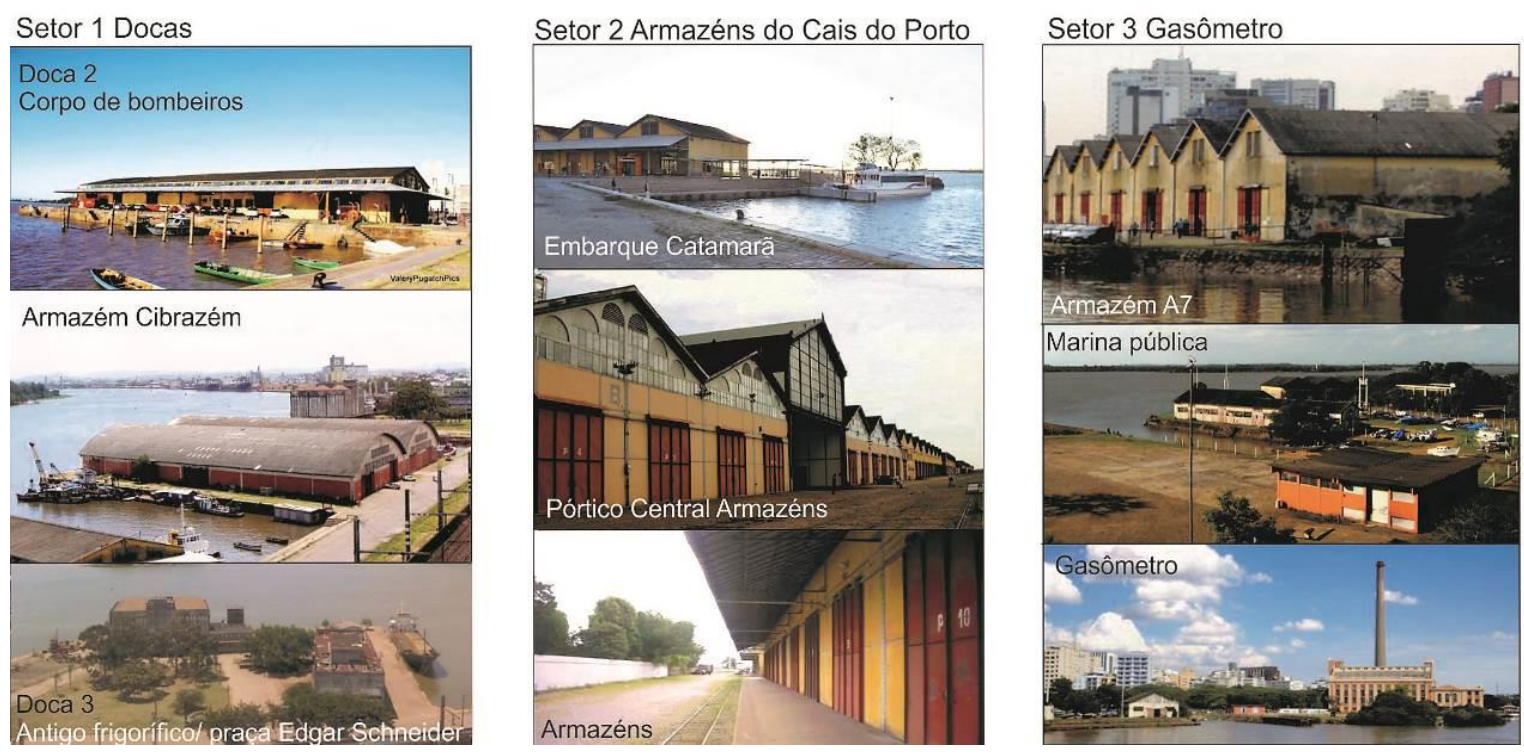

Fonte: antiga Secretaria de Planejamento Municipal (SPM) de Porto Alegre (GOOGLE..., 2012).

Figura 7 - Projeto de Revitalização dos três setores do Cais Mauá

Setor 1 Docas

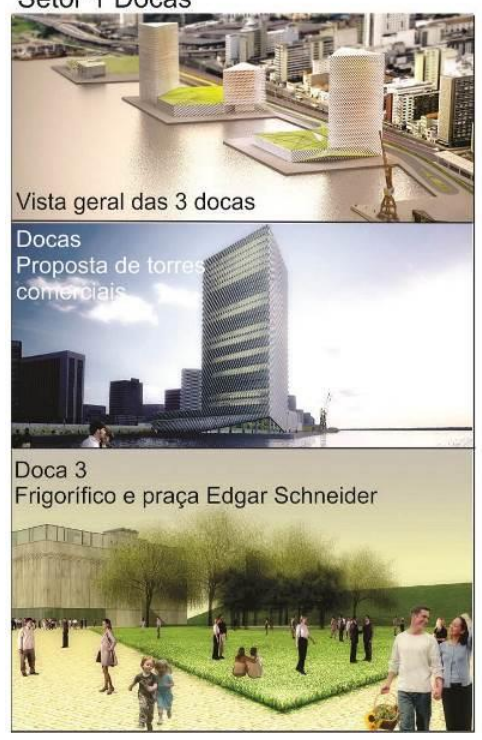

Fonte: Porto Imagem (2017).

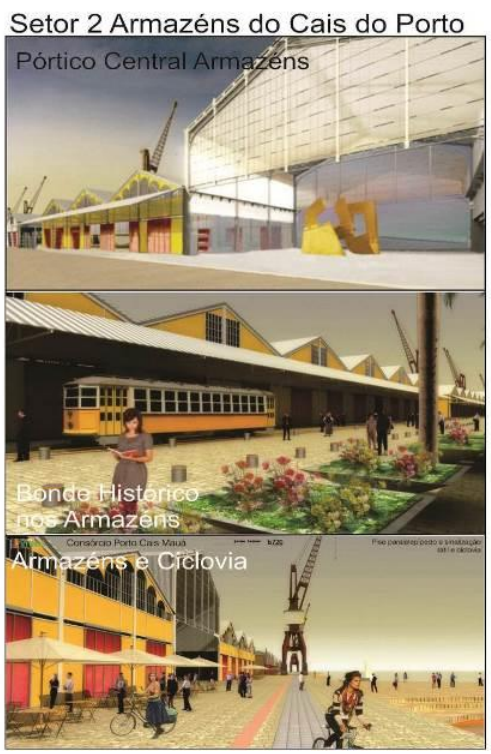

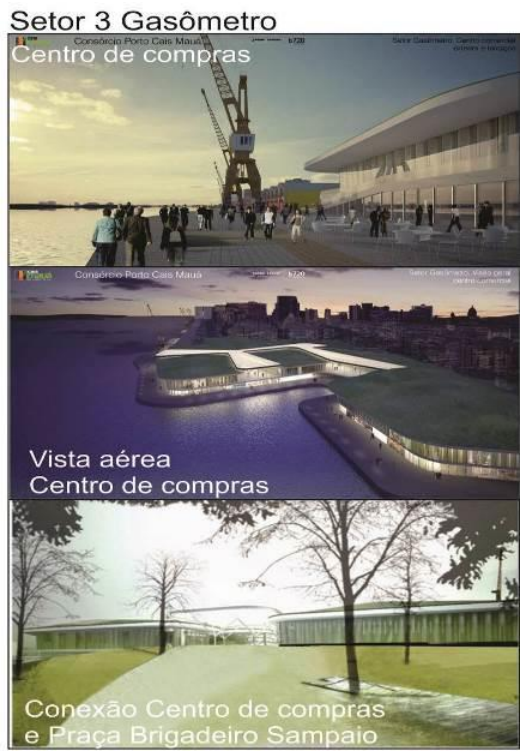

A amostra final é constituída por 128 respondentes, agrupados da seguinte forma:

(a) arquitetos $(45,31 \%$ - 58 de 128);

(b) não arquitetos com formação universitária $(39,71 \%$ - 54 de 128); e

(c) pessoas sem formação universitária $(11,76 \%$ 16 de 128).

Entretanto, 33,6\% (43 de 128) dos questionários tiveram menos de $50 \%$ de suas questões respondidas, assim distribuídos:

(a) arquitetos (31,03\% - 18 de 58); (b) não arquitetos com formação universitária (37,03\% - 20 de 54); e

(c) pessoas sem formação universitária $(31,25 \%$ 5 de 16).

Logo, foram considerados apenas os questionários de 85 respondentes, sendo:
(a) 40 arquitetos $(47,1 \%)$;
(b) 34 não arquitetos com formação universitária $(40 \%)$; e
(c) 11 pessoas sem formação universitária $(12,9 \%)$. 
Os dados obtidos por meio dos questionários foram exportados do programa LimeSurvey diretamente para a planilha do programa estatístico SPSS Statistics 17.0, o que reduziu significativamente o tempo utilizado para tabular tais dados e eliminou a possibilidade de erros na tabulação. As respostas de arquitetos e não arquitetos com formação universitária foram analisadas mediante testes estatísticos não paramétricos (tabulação cruzada - Phi, e Mann Whitney). Em função do numero reduzido de respondentes sem formação universitária, essa amostra não fez parte de tais testes não paramétricos, sendo analisada apenas por meio de frequências.

\section{Resultados}

Conforme os objetivos da investigação, são apresentados, a seguir, os resultados.

\section{Percepções e frequência de uso do Cais Mauá de acordo com os três grupos de respondentes}

A expressiva maioria dos respondentes $(94,1 \%$ 80 de 85) frequenta a área do Cais Mauá, tendência que se repetiu entre as respostas do grupo dos arquitetos (97,5\% - 39 de 40), dos não arquitetos com formação universitária $(88,2 \%$ - 30 de 34) e daqueles sem formação universitária (100\% - 11 de 11) (Tabela 1), e não há uma diferença estatisticamente significativa entre tais respostas (tabulação cruzada, Phi). Porém, existem claras diferenças entre os usos específicos de cada um dos três setores do Cais Mauá. A maioria dos respondentes $(76,5 \%$ - 65 de 85$)$ não frequenta o Setor 1 - Docas (Figuras 5 e 6), pelo que não há relação estatisticamente significativa (tabulação cruzada - Phi) entre o fato de frequentar tal setor e os grupos de arquitetos e não arquitetos com formação universitária (Tabela 1). Por outro lado, uma parte bastante expressiva dos respondentes frequenta o Setor 2 - Armazéns (85,9\% - 73 de 85) e o Setor 3 - Gasômetro (92,9\% - 79 de 85), tendência que se repete entre os três grupos de respondentes (Tabela 1).

Esses resultados tendem a se repetir em relação à frequência com que os setores são utilizados, visto que uma porcentagem alta do total dos respondentes $(76,3 \%$ - 61 de 80$)$ e de cada um dos três grupos analisados não tem utilizado o Setor 1 - Docas (Figuras 5 e 6), e não há relação estatisticamente significativa (tabulação cruzada, Phi) entre a frequência de uso e os grupos de arquitetos e não arquitetos com formação universitária (Tabela 2). O Setor 2 - Armazéns (Figuras 5 e 6), por sua vez, é frequentado pela maioria dos respondentes $(72,5 \%$ - 58 de 80$)$ no máximo quatro vezes ao ano, o que se repete para os três grupos avaliados, sem relação estatisticamente significativa (tabulação cruzada, Phi) entre a frequência de uso e os dois grupos com formação universitária. $\mathrm{O}$ Setor 3 Gasômetro (Figuras 5 e 6) também é frequentado pela maioria dos respondentes $(47,5 \%$ - 38 de 80$)$, no máximo, quatro vezes ao ano, e há uma relação estatisticamente significativa (tabulação cruzada, Phi $=0,428$, sig. $=0,035$ ) entre a frequência de uso de tal setor e os dois grupos com formação universitária, que se traduz em maior uso por parte dos arquitetos. Contudo, de maneira geral, verifica-se que os respondentes frequentam muito pouco os três setores analisados. 
Tabela 1 - Respondentes que frequentam o Cais Mauá

\begin{tabular}{|c|c|c|c|c|}
\hline Uso do Cais Mauá & Arquitetos & $\begin{array}{c}\text { Não arquitetos com } \\
\text { formação } \\
\text { universitária } \\
\end{array}$ & $\begin{array}{c}\text { Pessoas sem } \\
\text { formação } \\
\text { universitária } \\
\end{array}$ & Total \\
\hline Sim & $39(97,5 \%)$ & $30(88,2 \%)$ & $11(100 \%)$ & $80(94,1 \%)$ \\
\hline Não & $1(2,5 \%)$ & $4(11,8 \%)$ & $0(0 \%)$ & $5(5,9 \%)$ \\
\hline Total & $40(100 \%)$ & $34(100 \%)$ & $11(100 \%)$ & $85(100 \%)$ \\
\hline $\begin{array}{c}\text { Uso do Setor } 1 \text { - } \\
\text { Docas }\end{array}$ & Arquitetos & $\begin{array}{c}\text { Não arquitetos com } \\
\text { formação } \\
\text { universitária } \\
\end{array}$ & $\begin{array}{c}\text { Pessoas sem } \\
\text { formação } \\
\text { universitária } \\
\end{array}$ & Total \\
\hline Sim & $9(22,5 \%)$ & $8(23,5 \%)$ & $3(27,3 \%)$ & $20(23,5 \%)$ \\
\hline Não & $31(77,5 \%)$ & $26(76,5 \%)$ & $8(72,7 \%)$ & $65(76,5 \%)$ \\
\hline Total & $40(100 \%)$ & $34(100 \%)$ & $11(100 \%)$ & $85(100 \%)$ \\
\hline $\begin{array}{l}\text { Uso do Setor } 2 \text { - } \\
\text { Armazéns }\end{array}$ & Arquitetos & $\begin{array}{c}\text { Não arquitetos com } \\
\text { formação } \\
\text { universitária } \\
\end{array}$ & $\begin{array}{c}\text { Pessoas sem } \\
\text { formação } \\
\text { universitária } \\
\end{array}$ & Total \\
\hline Sim & $37(92,5 \%)$ & $26(76,5 \%)$ & $10(90,9 \%)$ & $73(85,9 \%)$ \\
\hline Não & $3(7,5 \%)$ & $8(23,5 \%)$ & $1(9,1 \%)$ & $12(14,1 \%)$ \\
\hline Total & $40(100 \%)$ & $34(100 \%)$ & $11(100 \%)$ & $85(100 \%)$ \\
\hline $\begin{array}{l}\text { Uso do Setor } 3 \text { - } \\
\text { Gasômetro }\end{array}$ & Arquitetos & $\begin{array}{c}\text { Não arquitetos com } \\
\text { formação } \\
\text { universitária } \\
\end{array}$ & $\begin{array}{c}\text { Pessoas sem } \\
\text { formação } \\
\text { universitária } \\
\end{array}$ & Total \\
\hline Sim & $39(97,5 \%)$ & $29(85,3 \%)$ & $11(100 \%)$ & $79(92,9 \%)$ \\
\hline Não & $1(2,5 \%)$ & $5(14,7 \%)$ & $0(0 \%)$ & $6(7,1 \%)$ \\
\hline Total & $40(100 \%)$ & $34(100 \%)$ & $11(100 \%)$ & $85(100 \%)$ \\
\hline
\end{tabular}

Tabela 2 - Frequência com que os respondentes frequentam o Cais Mauá de acordo com os setores

\begin{tabular}{c|c|c|c|c}
\hline Setor 1 - Docas & Arquiteto & Não arq c f univ & Resp s f univ & Total \\
\hline Mais de 4 vezes por mês & $0(0 \%)$ & $1(3,3 \%)$ & $0(0 \%)$ & $1(1,3 \%)$ \\
\hline 2 a 4 vezes por mês & $1(39 \%)$ & $0(0 \%)$ & $0(0 \%)$ & $1(1,3 \%)$ \\
\hline No máximo 1 vez ao mês & $0(0 \%)$ & $3(10 \%)$ & $1(9,1 \%)$ & $4(5 \%)$ \\
\hline No máximo 4 vezes ao ano & $5(12,8 \%)$ & $6(20 \%)$ & $2(18,2 \%)$ & $13(16,3 \%)$ \\
\hline Não tem utilizado o setor & $33(84,6 \%)$ & $20(66,7 \%)$ & $8(72,7 \%)$ & $61(76,3 \%)$ \\
\hline Total & $39(100 \%)$ & $30(100 \%)$ & $11(100 \%)$ & $80(100 \%)$ \\
\hline Setor 2 - Armazéns & Arquiteto & Não arq c f univ & Resp s f sup & Total \\
\hline 2 a 4 vezes por mês & $1(2,6 \%)$ & $0(0 \%)$ & $0(0 \%)$ & $1(1,3 \%)$ \\
\hline No máximo 1 vez ao mês & $0(0 \%)$ & $3(10 \%)$ & $0(0 \%)$ & $3(3,8 \%)$ \\
\hline No máximo 4 vezes ao ano & $31(79,5 \%)$ & $19(63,3 \%)$ & $8(72,7 \%)$ & $58(72,5 \%)$ \\
\hline Não tem utilizado o setor & $7(17,9 \%)$ & $8(26,7 \%)$ & $3(27,3 \%)$ & $18(22,5 \%)$ \\
\hline Total & $39(100 \%)$ & $30(100 \%)$ & $11(100 \%)$ & $80(100 \%)$ \\
\hline Setor 3 - Gasômetro & Arquiteto & Não arq c f univ & Resp s f univ & Total \\
\hline Diariamente & $0(0 \%)$ & $1(3,3 \%)$ & $0(0 \%)$ & $1(1,3 \%)$ \\
\hline Mais de 4 vezes por mês & $2(5,1 \%)$ & $0(0 \%)$ & $0(0 \%)$ & $2(2,5 \%)$ \\
\hline 2 a 4 vezes por mês & $9(23,1 \%)$ & $2(6,7 \%)$ & $0(0 \%)$ & $11(13,8 \%)$ \\
\hline No máximo 1 vez ao mês & $7(17,9 \%)$ & $11(36,7 \%)$ & $3(27,3 \%)$ & $21(26,3 \%)$ \\
\hline No máximo 4 vezes ao ano & $20(51,3 \%)$ & $12(40 \%)$ & $6(54,5 \%)$ & $38(47,5 \%)$ \\
\hline Não tem utilizado o setor & $1(2,6 \%)$ & $4(13,3 \%)$ & $2(18,2 \%)$ & $7(8,8 \%)$ \\
\hline Total & $39(100 \%)$ & $30(100 \%)$ & $11(100 \%)$ & $80(100 \%)$ \\
\hline
\end{tabular}

Nota: Legenda:

$\mathrm{N}$ arq $\mathrm{c} f$ univ = não arquiteto com formação universitária; $\mathrm{e}$

Resp $\mathrm{s} f$ univ $=$ respondente sem formação universitária. 
As principais razões citadas pelos respondentes sobre os motivos para frequentar o Setor 1 - Docas são (Tabela 3): os passeios de barco $(13,8 \%$ - 11 de 80) (Figura 8), admirar a paisagem $(11,3 \%-9$ de 80) (Figura 9) e participar de atividades culturais $(11,3 \%$ - 9 de 80). Essas são também as principais razões mencionadas para o uso do setor entre os três grupos avaliados.

Em relação à frequência de uso do Setor 2 Armazéns pelos respondentes, as principais justificativas são (Tabela 3):

\section{Figura 8 - Passeios de barco no Setor 1 - Docas}

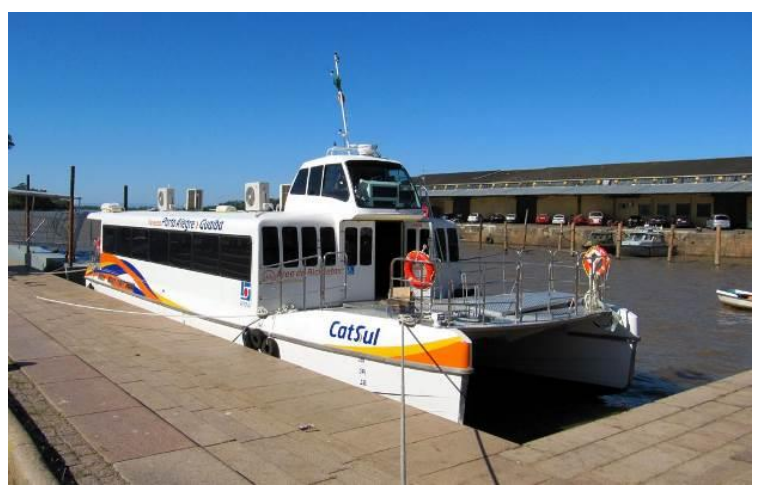

Figura 9 - Contemplação da paisagem

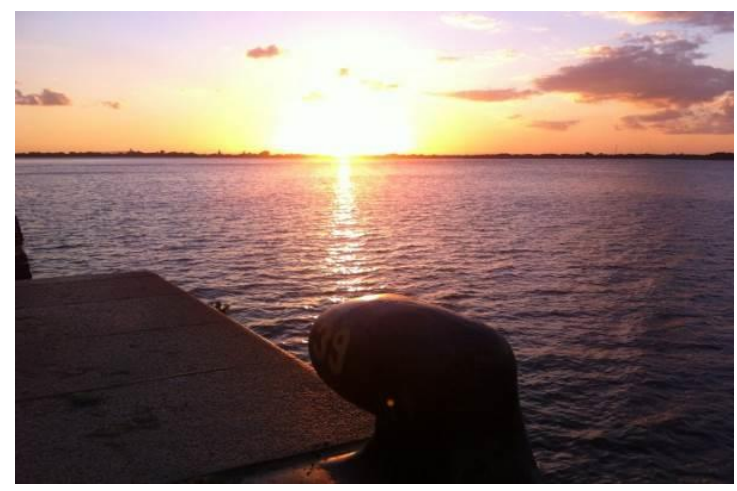

Figura 10 - Atividades culturais no Setor 2 - Armazéns

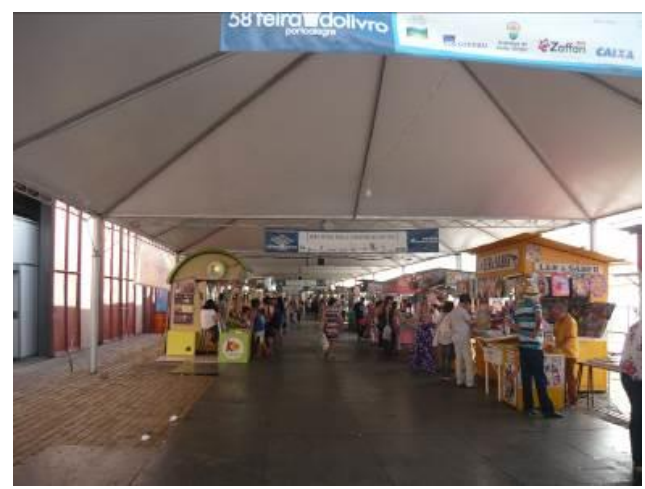

Antocheviz, F. B.; Reis, A. T. da L.; Limberger, L. R. L. (a) participação em atividades culturais (75\% - 60 de 80) (Figura 10);

(b) contemplação da paisagem $(28,8 \%$ - 23 de 80$)$ (Figura 11); e

(c) passeios no barco Cisne Branco (21,3\% - $17 \mathrm{de}$ 80) (Figura 12).

Ainda, estas são as principais razões para cada um dos três grupos para utilizar o Setor 2 . 
Figura 11 - Contemplação da paisagem no Setor 2 - Armazéns

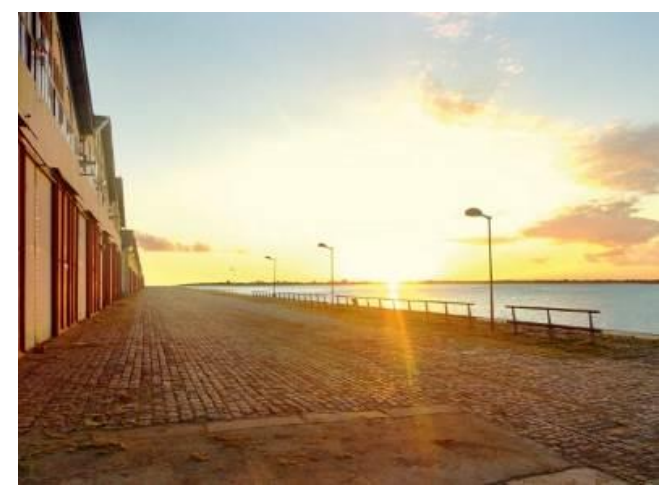

Figura 12 - Passeios de barco no Cisne Branco no Setor 2 - Armazéns

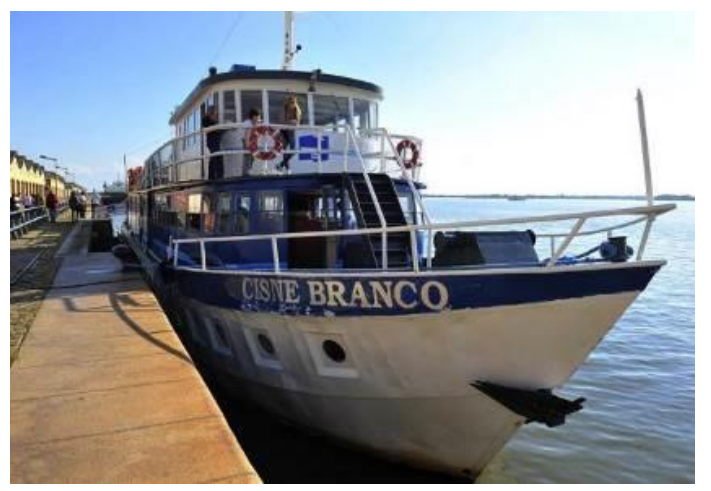

Por sua vez, os principais motivos para os respondentes utilizarem o Setor 3 - Gasômetro são (Tabela 3):

(a) contemplação da paisagem $(76,3 \%$ - 61 de 80$)$ (Figura 13);

(b) participação em atividades culturais $(70 \%$ - 56 de

80) (Figura 14);

(c) passeios de barco $(31,3 \%$ - 25 de 80$)$; e

(d) prática de esportes $(26,3 \%$ - 21 de 80$)$ (Figura 15).

Adicionalmente, estas foram as principais razões citadas por cada um dos três grupos para utilizar este setor.

Não foram encontradas relações estatisticamente significativas (tabulação cruzada - Phi) entre as razões mencionadas para utilizar cada um dos três setores e os dois grupos com formação universitária. Considerando o número total de vezes em que cada razão foi mencionada, os principais motivos para os respondentes utilizarem os três setores do Cais Mauá são: participação em atividades culturais $(9+60+56$ = 125); contemplação da paisagem $(9+23+61=93)$; passeios de barco $(11+17+25=53)$; e prática de esportes (21) (Tabela 3).
Os aspectos no Setor 1 - Docas (Figuras 5 e 6) (Tabela 4) avaliados como insatisfatórios pela maioria dos respondentes são:

(a) facilidade de acesso ao setor (60\% - 12 de 20);

(b) restrição do acesso de pedestres a algumas partes do Setor 1 devido ao seu uso privado $(65 \%$ - 13 de 20); e

(c) uso privativo dos armazéns C2 (45\% - 9 de 20), C3 (55\% - 8 de 20) e CIBRAZEM (65\% - 13 de 20).

Portanto, grande parte dos respondentes se mostrou insatisfeita com o uso privado e o acesso restrito ao Setor 1 - Docas. Foram encontradas diferenças estatisticamente significativas entre arquitetos e não arquitetos com formação universitária em relação ao grau de adequação de três aspectos (de dez aspectos analisados) no Setor 1 - Docas: facilidade de acesso do pedestre ao setor (Mann-Whitney, $\mathrm{chi}^{2}=8,972$, sig. = 0,004); uso do Armazém C2 pelo Corpo de Bombeiros Naval (Mann-Whitney, chi $^{2}=6,464$, sig. $=$ 0,049); e a proibição de sócios do Clube Grêmio Náutico União estacionarem na área interna das Docas (Mann-Whitney, chi $^{2}=7,634$, sig $=0,010$ ). Enquanto a maioria dos arquitetos avalia esses aspectos como inadequados, os não arquitetos com formação universitária tendem a avaliá-los como adequados. 
Tabela 3 - Razões para frequentar os setores e formação dos respondentes

\begin{tabular}{c|c|c|c|c}
\hline Setor 1 - Docas & Arquiteto & Não arq c f univ & Resp s f univ & Total \\
\hline Passeio de barco & $3(7,7 \%)$ & $5(16,7 \%)$ & $3(27,3 \%)$ & $11(13,8 \%)$ \\
\hline Admirar a paisagem & $2(5,1 \%)$ & $6(20 \%)$ & $1(9,1 \%)$ & $9(11,3 \%)$ \\
\hline Atividades culturais & $4(10,3 \%)$ & $4(13,3 \%)$ & $1(9,1 \%)$ & $9(11,3 \%)$ \\
\hline Prática de esportes & $3(7,7 \%)$ & $0(0 \%)$ & $1(9,1 \%)$ & $4(5 \%)$ \\
\hline Não tem utilizado & $1(2,6 \%)$ & $1(3,3 \%)$ & $0(0 \%)$ & $2(2,5 \%)$ \\
\hline Trabalha no local & $0(0 \%)$ & $0(0 \%)$ & $0(0 \%)$ & $0(0 \%)$ \\
\hline Total & $39(100 \%)$ & $30(100 \%)$ & $11(100 \%)$ & $80(100 \%)$ \\
\hline Setor 2 - Armazéns & Arquiteto & Não arq c f univ & Resp s f univ & Total \\
\hline Atividades culturais & $30(76,9 \%)$ & $21(70 \%)$ & $9(81,8 \%)$ & $60(75 \%)$ \\
\hline Admirar a paisagem & $10(25,6 \%)$ & $10(33,3 \%)$ & $3(27,3 \%)$ & $23(28,8 \%)$ \\
\hline Passeio de barco & $6(15,4 \%)$ & $9(30 \%)$ & $2(18,2 \%)$ & $17(21,3 \%)$ \\
\hline Não tem utilizado & $4(10,3 \%)$ & $2(6,7 \%)$ & $1(9,1 \%)$ & $7(8,8 \%)$ \\
\hline Locomoção Catamarã & $3(7,7 \%)$ & $3(10 \%)$ & $0(0 \%)$ & $6(7,5 \%)$ \\
\hline Trabalha no local & $1(2,6 \%)$ & $0(0 \%)$ & $0(0 \%)$ & $1(1,3 \%)$ \\
\hline Prática de esportes & $0(0 \%)$ & $1(3,3 \%)$ & $0(0 \%)$ & $1(1,3 \%)$ \\
\hline Total & $39(100 \%)$ & $30(100 \%)$ & $11(100 \%)$ & $80(100 \%)$ \\
\hline Setor 3 - Gasômetro & Arquiteto & Não arq c f univ & Resp s f univ & Total \\
\hline Admirar a paisagem & $31(79,5 \%)$ & $22(73,3 \%)$ & $8(72,7 \%)$ & $61(76,3 \%)$ \\
\hline Atividades culturais & $28(71,8 \%)$ & $22(73,3 \%)$ & $6(54,5 \%)$ & $56(70 \%)$ \\
\hline Passeio de barco & $10(25,6 \%)$ & $9(30 \%)$ & $6(54,5 \%)$ & $25(31,3 \%)$ \\
\hline Prática de esportes & $15(38,5 \%)$ & $4(13,3 \%)$ & $2(18,2 \%)$ & $21(26,3 \%)$ \\
\hline Não tem utilizado & $1(2,6 \%)$ & $3(10 \%)$ & $1(9,1 \%)$ & $5(6,3 \%)$ \\
\hline Trabalha no local & $0(0 \%)$ & $1(3,3 \%)$ & $0(0 \%)$ & $1(1,3 \%)$ \\
\hline Total & $39(100 \%)$ & $30(100 \%)$ & $11(100 \%)$ & $80(100 \%)$ \\
\hline Nota) & & & \\
\hline
\end{tabular}

Nota: Legenda:

$\mathrm{N}$ arq $\mathrm{c} f$ univ = não arquiteto com formação universitária; $\mathrm{e}$

Resp $\mathrm{s} f$ univ = respondente sem formação universitária.

Figura 13 - Contemplação da paisagem no Setor 3 - Gasômetro

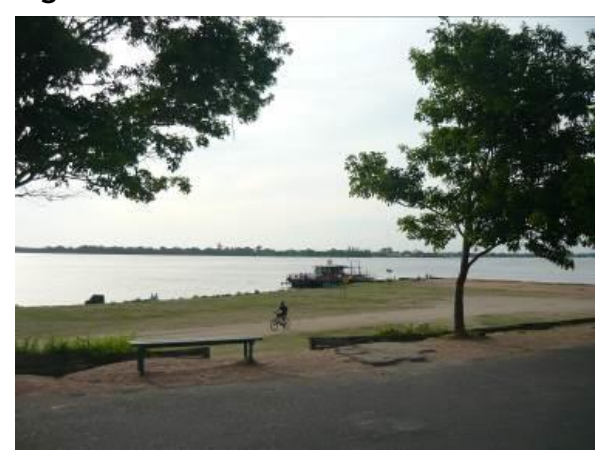

Figura 14 - Atividades culturais no Setor 3 - Gasômetro

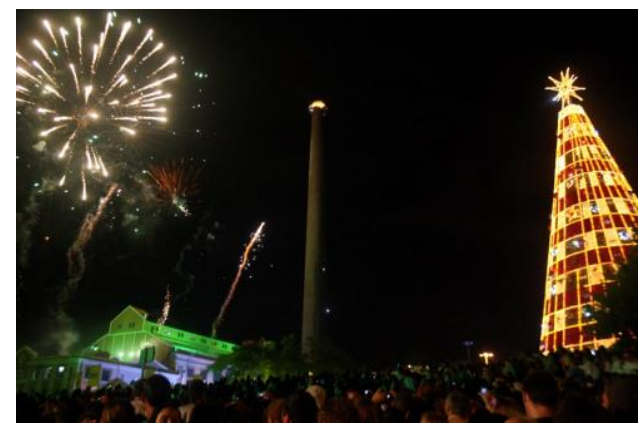

Fonte: Viajar é simples (2017). 
Figura 15 - Prática de esportes no Setor 3 - Gasômetro

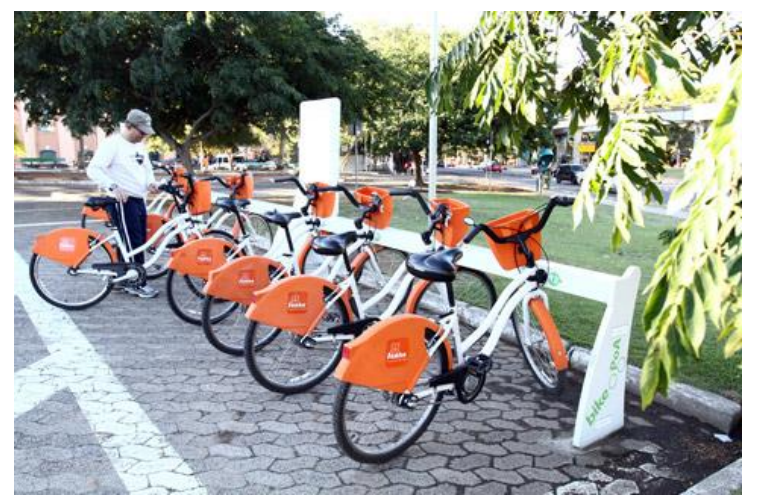

Tabela 4 - Opiniões dos respondentes no tocante a aspectos relacionados aos três setores da orla (Continua...)

\begin{tabular}{|c|c|c|c|c|c|c|}
\hline & MA & Adequado & $\mathbf{N N}$ & Inadequado & MI & Total \\
\hline \multicolumn{7}{|c|}{ Setor 1 - Docas } \\
\hline \multicolumn{7}{|c|}{ Facilidade de acesso de pedestres } \\
\hline Arquiteto & $0(0 \%)$ & $0(0 \%)$ & $1(11,1 \%)$ & $4(44,4 \%)$ & $4(44,4 \%)$ & $9(100 \%)$ \\
\hline Não arq c f sup & $0(0 \%)$ & $4(50 \%)$ & $2(25 \%)$ & $2(25 \%)$ & $0(0 \%)$ & $8(100 \%)$ \\
\hline Resp s f sup & $0(0 \%)$ & $0(0 \%)$ & $1(33,3 \%)$ & $1(33,3 \%)$ & $1(33,3 \%)$ & $3(100 \%)$ \\
\hline Total & $0(0 \%)$ & $4(20 \%)$ & $4(20 \%)$ & $7(35 \%)$ & $5(25 \%)$ & $20(100 \%)$ \\
\hline \multicolumn{7}{|c|}{ Acesso restrito de pedestres devido a alguns usos particulares existentes no setor } \\
\hline Arquiteto & $0(0 \%)$ & $0(0 \%)$ & $3(33,3 \%)$ & $4(44,4 \%)$ & $2(22,2 \%)$ & $9(100 \%)$ \\
\hline Não arq c f sup & $0(0 \%)$ & $1(12,5 \%)$ & $2(25 \%)$ & $1(12,5 \%)$ & $4(50 \%)$ & $8(100 \%)$ \\
\hline Resp s f sup & $0(0 \%)$ & $0(0 \%)$ & $1(33,3 \%)$ & $0(0 \%)$ & $2(66,7 \%)$ & $3(100 \%)$ \\
\hline Total & $0(0 \%)$ & $1(5 \%)$ & $6(30 \%)$ & $5(25 \%)$ & $8(40 \%)$ & $20(100 \%)$ \\
\hline \multicolumn{7}{|c|}{ Proibição de estacionamento na área interna do Cais do Porto pelos sócios do Grêmio Náutico União } \\
\hline Arquiteto & $0(0 \%)$ & $1(11,1 \%)$ & $2(22,2 \%)$ & $5(55,6 \%)$ & $1(11,1 \%)$ & $9(100 \%)$ \\
\hline Não arq c f sup & $4(50 \%)$ & $1(12,5 \%)$ & $2(25 \%)$ & $1(12,5 \%)$ & $0(0 \%)$ & $8(100 \%)$ \\
\hline Resp s f sup & $0(0 \%)$ & $0(0 \%)$ & $1(33,3 \%)$ & $1(33,3 \%)$ & $1(33,3 \%)$ & $3(100 \%)$ \\
\hline Total & $4(20 \%)$ & $2(10 \%)$ & $5(25 \%)$ & $7(35 \%)$ & $2(10 \%)$ & $20(100 \%)$ \\
\hline \multicolumn{7}{|c|}{ Setor 2 - Armazéns } \\
\hline \multicolumn{7}{|c|}{ Facilidade de acesso de pedestres } \\
\hline Arquiteto & $1(2,7 \%)$ & $4(10,8 \%)$ & $9(24,3 \%)$ & $20(54,1 \%)$ & $3(8,1 \%)$ & $37(100 \%)$ \\
\hline Não arq c f sup & $2(7,7 \%)$ & $5(19,2 \%)$ & $12(46,2 \%)$ & $6(23,1 \%)$ & $1(3,8 \%)$ & $26(100 \%)$ \\
\hline Resp s f sup & $1(10 \%)$ & $2(20 \%)$ & $1(10 \%)$ & $5(50 \%)$ & $1(10 \%)$ & $10(100 \%)$ \\
\hline Total & $4(5,5 \%)$ & $11(15,1 \%)$ & $22(30,1 \%)$ & $31(42,5 \%)$ & $5(6,8 \%)$ & $73(100 \%)$ \\
\hline \multicolumn{7}{|c|}{ Embarque/desembarque em terminal hidroviário } \\
\hline Arquiteto & $3(8,1 \%)$ & $7(18,9 \%)$ & $20(54,1 \%)$ & $6(16,2 \%)$ & $1(2,7 \%)$ & $37(100 \%)$ \\
\hline Não arq c f sup & $3(11,5 \%)$ & $12(46,2 \%)$ & $9(34,6 \%)$ & $0(0 \%)$ & $2(7,7 \%)$ & $26(100 \%)$ \\
\hline Resp s f sup & $2(20 \%)$ & $2(20 \%)$ & $4(40 \%)$ & $2(20 \%)$ & $0(0 \%)$ & $10(100 \%)$ \\
\hline Total & $8(11 \%)$ & $21(28,8 \%)$ & $33(45,2 \%)$ & $8(11 \%)$ & $3(4,1 \%)$ & $73(100 \%)$ \\
\hline \multicolumn{7}{|c|}{ Uso cultural dos Armazéns para exposições e feiras } \\
\hline Arquiteto & $13(35,1 \%)$ & $15(40,5 \%)$ & $5(13,5 \%)$ & $3(8,1 \%)$ & $1(2,7 \%)$ & $37(100 \%)$ \\
\hline Não arq c f sup & $4(15,4 \%)$ & $14(53,8 \%)$ & $6(23,1 \%)$ & $1(3,8 \%)$ & $1(3,8 \%)$ & $26(100 \%)$ \\
\hline Resp s f sup & $5(50 \%)$ & $4(40 \%)$ & $1(10 \%)$ & $0(0 \%)$ & $0(0 \%)$ & $10(100 \%)$ \\
\hline Total & $22(30,1 \%)$ & $33(45,2 \%)$ & $12(16,4 \%)$ & $4(5,5 \%)$ & $2(2,7 \%)$ & $73(100 \%)$ \\
\hline \multicolumn{7}{|c|}{ Acesso de pedestres restrito em áreas do setor } \\
\hline Arquiteto & $0(0 \%)$ & $5(13,5 \%)$ & $12(32,4 \%)$ & $12(32,4 \%)$ & $8(21,6 \%)$ & $37(100 \%)$ \\
\hline Não arq c f sup & $2(7,7 \%)$ & $4(15,4 \%)$ & $12(46,2 \%)$ & $4(15,4 \%)$ & $4(15,4 \%)$ & $26(100 \%)$ \\
\hline Resp s f sup & $0(0 \%)$ & $1(10 \%)$ & $3(30 \%)$ & $4(40 \%)$ & $2(20 \%)$ & $10(100 \%)$ \\
\hline Total & $2(2,7 \%)$ & $10(13,7 \%)$ & $27(37 \%)$ & $20(37 \%)$ & $14(27,4 \%)$ & $73(100 \%)$ \\
\hline
\end{tabular}


Tabela 4 - Opiniões dos respondentes no tocante a aspectos relacionados aos três setores da orla (continuação)

\begin{tabular}{|c|c|c|c|c|c|c|}
\hline \multicolumn{7}{|c|}{ Acesso restrito de veículos no Cais Mauá } \\
\hline Arquiteto & $2(5,4 \%)$ & $5(13,5 \%)$ & $9(24,3 \%)$ & $11(29,7 \%)$ & $10(27 \%)$ & $37(100 \%)$ \\
\hline Não arq c f sup & $1(3,8 \%)$ & $4(15,4 \%)$ & $7(26,9 \%)$ & $8(30,8 \%)$ & $6(23,1 \%)$ & $26(100 \%)$ \\
\hline Resp s f sup & $0(0 \%)$ & $0(0 \%)$ & $4(40 \%)$ & $4(40 \%)$ & $2(20 \%)$ & $10(100 \%)$ \\
\hline Total & $3(4,1 \%)$ & $9(12,3 \%)$ & $20(37 \%)$ & $23(31,5 \%)$ & $18(24,7 \%)$ & $73(100 \%)$ \\
\hline \multicolumn{7}{|c|}{ Setor 3 - Gasômetro } \\
\hline \multicolumn{7}{|c|}{ Contemplação das visuais do Guaíba } \\
\hline Arquiteto & $13(33,3 \%)$ & $19(48,7 \%)$ & $5(12,8 \%)$ & $2(5,1 \%)$ & $0(0 \%)$ & $39(100 \%)$ \\
\hline Não arq c f sup & $4(13,8 \%)$ & $16(55,2 \%)$ & $5(17,2 \%)$ & $3(10,3 \%)$ & $1(3,4 \%)$ & $29(100 \%)$ \\
\hline Resp s f sup & $4(36,4 \%)$ & $1(9,1 \%)$ & $2(18,2 \%)$ & $3(27,3 \%)$ & $1(9,1 \%)$ & $11(100 \%)$ \\
\hline Total & $21(26,6 \%)$ & $36(45,6 \%)$ & $12(15,2 \%)$ & $8(10,1 \%)$ & $2(2,5 \%)$ & $79(100 \%)$ \\
\hline \multicolumn{7}{|c|}{ Uso cultural da Usina do Gasômetro para exposições e feiras } \\
\hline Arquiteto & $15(38,5 \%)$ & $18(46,2 \%)$ & $4(10,3 \%)$ & $1(2,6 \%)$ & $1(2,6 \%)$ & $39(100 \%)$ \\
\hline Não arq c f sup & $5(17,2 \%)$ & $17(58,6 \%)$ & $4(13,8 \%)$ & $2(6,9 \%)$ & $1(3,4 \%)$ & $29(100 \%)$ \\
\hline Resp s f sup & $5(45,5 \%)$ & $5(45,5 \%)$ & $1(9,1 \%)$ & $0(0 \%)$ & $0(0 \%)$ & $11(100 \%)$ \\
\hline Total & $25(31,6 \%)$ & $40(50,6 \%)$ & $9(11,4 \%)$ & $3(3,8 \%)$ & $2(2,5 \%)$ & $79(100 \%)$ \\
\hline \multicolumn{7}{|c|}{ Uso para caminhada/corrida } \\
\hline Arquiteto & $19(48,7 \%)$ & $16(42,1 \%)$ & $2(5,1 \%)$ & $2(5,1 \%)$ & $0(0 \%)$ & $39(100 \%)$ \\
\hline Não arq c f sup & $11(37,9 \%)$ & $11(37,9 \%)$ & $3(10,3 \%)$ & $1(3,4 \%)$ & $3(10,3 \%)$ & $29(100 \%)$ \\
\hline Resp s f sup & $6(54,5 \%)$ & $4(36,4 \%)$ & $0(0 \%)$ & $0(0 \%)$ & $1(9,1 \%)$ & $11(100 \%)$ \\
\hline Total & $36(45,6 \%)$ & $31(39,2 \%)$ & $5(6,3 \%)$ & $3(3,8 \%)$ & $4(5,1 \%)$ & $79(100 \%)$ \\
\hline \multicolumn{7}{|c|}{ Uso recreativo pelos ciclistas } \\
\hline Arquiteto & $16(42,1 \%)$ & $15(39,5 \%)$ & $4(10,3 \%)$ & $3(7,7 \%)$ & $0(0 \%)$ & $39(100 \%)$ \\
\hline Não arq c f sup & $7(24,1 \%)$ & $13(44,8 \%)$ & $3(10,3 \%)$ & $3(10,3 \%)$ & $3(10,3 \%)$ & $29(100 \%)$ \\
\hline Resp s f sup & $7(63,6 \%)$ & $3(27,3 \%)$ & $0(0 \%)$ & $0(0 \%)$ & $1(9,1 \%)$ & $11(100 \%)$ \\
\hline Total & $30(38,5 \%)$ & $31(39,7 \%)$ & $7(9 \%)$ & $6(7,7 \%)$ & $4(5,1 \%)$ & $79(100 \%)$ \\
\hline \multicolumn{7}{|c|}{ Quantidade de vagas de estacionamento ao lado da Usina do Gasômetro } \\
\hline Arquiteto & $1(2,6 \%)$ & $8(20,5 \%)$ & $9(23,1 \%)$ & $17(43,6 \%)$ & $4(10,3 \%)$ & $39(100 \%)$ \\
\hline Não arq c f sup & $0(0 \%)$ & $6(21,4 \%)$ & $9(32,1 \%)$ & $9(32,1 \%)$ & $4(13,8 \%)$ & $28(100 \%)$ \\
\hline Resp s f sup & $0(0 \%)$ & $2(18,2 \%)$ & $2(18,2 \%)$ & $7(63,6 \%)$ & $0(0 \%)$ & $11(100 \%)$ \\
\hline Total & $1(1,3 \%)$ & $16(20,5 \%)$ & $20(25,6 \%)$ & $33(42,3 \%)$ & $8(10,3 \%)$ & $78(100 \%)$ \\
\hline \multicolumn{7}{|c|}{ Manutenção e limpeza dos sanitários existentes } \\
\hline Arquiteto & $0(0 \%)$ & $2(5,1 \%)$ & $8(20,5 \%)$ & $18(46,2 \%)$ & $11(28,2 \%)$ & $39(100 \%)$ \\
\hline Não arq c f sup & $0(0 \%)$ & $1(3,6 \%)$ & $3(10,7 \%)$ & $10(35,7 \%)$ & $14(50 \%)$ & $28(100 \%)$ \\
\hline Resp s f sup & $0(0 \%)$ & $1(9,1 \%)$ & $3(27,3 \%)$ & $4(36,4 \%)$ & $3(27,3 \%)$ & $11(100 \%)$ \\
\hline Total & $0(0 \%)$ & $4(5,1 \%)$ & $14(17,9 \%)$ & $32(41 \%)$ & $28(35,9 \%)$ & $78(100 \%)$ \\
\hline $\begin{array}{l}\text { egenda: } \\
\mathrm{N} \text { arq c f } s \\
\text { Resp s f s } \\
\mathrm{MA}=\text { Muit } \\
\mathrm{NN}=\text { Nem } \\
\mathrm{Ml}=\text { Muito }\end{array}$ & $\begin{array}{l}\text { sponden } \\
\text { uado; } \\
\text { ido nem }\end{array}$ & formação & $\begin{array}{l}\text { erior; } \\
\text { ior; }\end{array}$ & & & \\
\hline
\end{tabular}

Os aspectos no Setor 2 - Armazéns (Figuras 5 e 6) (Tabela 4) foram considerados inadequados por um número expressivo do total de respondentes e de cada um dos três grupos. Assim como no Setor 1 - Docas, aspectos relacionados à privatização do espaço público são percebidos como inadequados por uma parcela significativa dos respondentes, tais como o acesso restrito de pedestres $(64,4 \%$ 34 de 73$)$ e de veículos $(56,2 \%$ - 41 de 73$)$. Foram encontradas diferenças estatisticamente significativas entre arquitetos e não arquitetos com formação universitária em relação ao grau de adequação de dois aspectos (de 16 aspectos analisados) no Setor 2 - Armazéns:

(a) facilidade de acesso dos pedestres à área (Mann-Whitney, chi $^{2}=7,726$, sig. = 0,011); e

(b) o embarque e desembarque de passageiros no terminal hidroviário (Mann-Whitney Test, chi $^{2}=$ 0,212, sig. = 0,030).

Os arquitetos tendem a avaliar esses aspectos como mais inadequados que os não arquitetos com 
formação universitária. Apenas os seguintes aspectos relacionados a eventos culturais são considerados apropriados:

(a) uso cultural da área por adultos (ex.: Feira do Livro, feiras em geral, bienais do Mercosul, peças de teatro e apresentações da Orquestra Sinfônica de Porto Alegre - OSPA; 79,5\% - 58 de 73);

(b) uso dos armazéns para exposições e feiras (75,3\% - 55 de 73$)$; e

(c) uso cultural por crianças (peças de teatro, feiras, concertos, jogos infantis 63\% - 46 de 73).

Logo, os níveis de satisfação dos usuários com esses eventos indicam a importância de incentivar esse tipo de uso no Setor 2.

Diferentemente dos outros dois setores, aspectos relacionados ao Setor 3 - Gasômetro (Figuras 3 e 4) (Tabela 4) foram avaliados como adequados por grande parte do total dos respondentes, e de cada um dos três grupos. Os respondentes identificaram usos culturais e de lazer e a prática de esportes como os tipos de usos mais adequados no Setor 3:

(a) caminhadas $(84,8 \%$ - 67 de 79$)$;

(b) uso cultural do Gasômetro (82\% - 65 de 79);

(c) andar de bicicleta $(78,2 \%$ - 61 de 79); e

(d) contemplação do Lago Guaíba (72,2\% - 57 de 79).

Entretanto, um número expressivo de respondentes avaliou aspectos relacionados à infraestrutura do Setor 3 - Gasômetro como inadequados, tais como o número reduzido de vagas de estacionamento (52,6\% - 41 de 78$)$ e a manutenção e limpeza dos banheiros públicos existentes (78,2\% - 61 de 78). Uma diferença estatisticamente significativa (teste Mann-Whitney, chi $^{2}=4,56$, sig. $=0,049$ ) entre a percepção dos arquitetos e dos não arquitetos com formação universitária foi encontrada apenas em relação ao grau de adequação de contemplação do Lago Guaíba (entre 18 aspectos analisados) no Setor 3 - Gasômetro. Os arquitetos tendem a achar tal aspecto mais adequado do que os não arquitetos com formação universitária. Com relação aos aspectos que devem ser melhorados no Cais Mauá, conforme as percepções dos respondentes, estão aqueles relacionados, principalmente, a melhorias na infraestrutura local e à promoção de atividades culturais e de lazer, sendo elas:
(a) condições de acesso ao local (17,9\% - 14 de 78);
(b) áreas de estar sombreadas (10,3\% - 8 de 78);
(c) segurança quanto ao crime (9\% - 7 de 78$)$;
(d) conservação e limpeza da área $(7,7 \%$ - 6 de 78);

(e) áreas de recreação públicas (7,7\% - 6 de 78); e

(f) calçadas para pedestres e áreas de estacionamento $(6,4 \%-5$ de 78$)$.

Esses aspectos são similares aos principais aspectos mencionados pelos respondentes de cada um dos três grupos.

\section{Percepção dos usuários a respeito das diretrizes da Prefeitura e de diretrizes propostas pelos pesquisadores}

Além das seis diretrizes propostas pela Prefeitura de Porto Alegre para a orla, os respondentes também avaliaram quatro diretrizes propostas pelos pesquisadores:

(a) incentivar a preservação das edificações existentes na área, sem a construção de novos edifícios;

(b) promover o uso residencial em algumas partes dos setores;

(c) permitir a construção de novos edifícios mais altos que os armazéns; e

(d) promover o uso para escritórios em algumas partes dos setores.

A grande maioria dos respondentes concorda ou concorda fortemente com as seis diretrizes propostas pela Prefeitura para a Orla, conforme segue:

(a) incentivar o uso dos setores com a criação de uma área de circulação de pedestres no Guaíba (95,9\% - concordam ou concordam muito);

(b) proporcionar a reintegração da população na orla, por meio de atividades relacionadas com o uso da água $(94,6 \%)$;

(c) proporcionar a valorização e a preservação dos espaços abertos, privilegiando a vegetação e a paisagem $(93,1 \%)$;

(d) otimizar a implantação de atividades que explorem a conexão visual com o Guaíba (ex.: bares e restaurantes) $(91,8 \%)$;

(e) ser de livre acesso à população, com usos públicos $(91,7 \%)$; e

(f) reciclar o uso dos armazéns a fim de preservar as edificações existentes, favorecendo a cultura e o turismo $(90,4 \%)$.

Em relação a essas seis diretrizes da Prefeitura não foram encontradas diferenças estatisticamente significativas entre as opiniões de arquitetos e não arquitetos com formação universitária. 
Com relação às diretrizes propostas pelos pesquisadores, o número de respondentes que concorda com a diretriz de incentivar a preservação de edificações existentes na área sem novas construções $(38,3 \%)$ é apenas um pouco maior do que o número de respondentes que discorda $(32,8 \%)$, o que revela opiniões opostas entre os respondentes. Nesse sentido, foi encontrada uma diferença estatisticamente significativa (teste Mann-Whitney, $\mathrm{chi}^{2}=5,346$, sig. $=0,029)$ entre arquitetos $(29,4 \%$ concorda ou concorda fortemente e $41,2 \%$ discorda ou discorda fortemente) e não arquitetos com formação universitária $(50 \%$ concorda ou concorda fortemente e $20 \%$ discorda ou discorda fortemente). Portanto, enquanto predomina claramente para os não arquitetos com formação universitária a oposição à construção de novos edifícios no Cais Mauá, para os arquitetos predomina a aprovação de novas construções. Por outro lado, a maioria dos respondentes discorda ou discorda totalmente das seguintes diretrizes propostas para a orla: proporcionar o uso residencial em partes dos setores $(58,9 \%)$; permitir novas construções com altura superior à dos armazéns $(52,1 \%)$. Com relação a essas duas diretrizes não foram encontradas diferenças estatisticamente significativas entre as percepções de arquitetos e de não arquitetos com formação universitária. Sendo assim, os arquitetos tendem a aprovar a construção de novas edificações, mas não com altura superior as dos armazéns.

O número de respondentes que discorda $(38,4 \%)$ prevalece claramente sobre aqueles que concordam $(19,2 \%)$ com a diretriz de proporcionar o uso para escritórios em partes dos setores, havendo uma diferença estatisticamente significativa (teste Mann-Whitney, chi $^{2}=11,359$, sig. $=0,03$ ) entre as opiniões dos dois grupos. Enquanto entre os arquitetos predomina visivelmente a concordância (47\%) sobre a discordância $(23,5 \%)$, entre os não arquitetos com formação universitária prevalece expressivamente a discordância $(56,6 \%)$ sobre a concordância $(13,4 \%)$ com a diretriz de prover uso para escritórios em partes dos setores.

\section{Projeto de revitalização do Cais Mauá e a percepção dos usuários da área}

Quantidades expressivas de respondentes discordam do projeto de revitalização do Cais Mauá no tocante ao uso privado do Setor 1 Docas com a proposta de construção de três torres com altura de 100 metros $(65,3 \%$ - 47 de 72$)$, duas para escritórios $(57 \%$ - 41 de 72$)$ e uma para hotel $(40,3 \%$ - 29 de 72). Por outro lado, os respondentes concordam com a promoção de atividades culturais na área, tais como o uso do edifício do antigo frigorífico como um centro cultural $(95,8 \%$ - 69 de 72) e a transformação da Praça Edgar Schneider em um anfiteatro elevado e gramado (76,4\% - 55 de 72). Resultados similares foram obtidos em cada um dos três grupos, não tendo sido encontrada diferença estatisticamente significativa (teste Mann-Whitney) entre as percepções de arquitetos e não arquitetos com formação universitária.

Diferentemente do Setor 1 - Docas, a expressiva maioria dos respondentes concorda ou concorda totalmente com a maior parte das diretrizes propostas para o Setor 2 - Armazéns, incluindo aspectos relacionados a usos para lazer, tais como:

(a) promover o uso dos armazéns como restaurantes, bares, bistrôs e cafés $(98,6 \%$ - 70 de 71);

(b) encorajar a implantação de uma linha de bonde turística na área $(98,6 \%$ - 70 de 71$)$; e

(c) criar praças flutuantes na beira do Lago Guaíba $(76,1 \%$ - 54 de 71).

Os respondentes também concordam com a promoção de usos culturais e educacionais no projeto para o Setor 2, tais como a implementação de um Campus da Universidade Federal do Rio Grande do Sul, do Museu de Arte Contemporânea e de um centro de formação de jovens $(83,1 \%$ - 59 de 71). Ainda, os respondentes concordam com a inclusão no projeto de revitalização de áreas para prática de esportes no Setor 2, tal como a criação de um caminho para pedestres ao longo dos Armazéns (97,1\% - 69 de 71) e a inserção de uma ciclovia na área $(74,6 \%$ - 53 de 71). Esses tipos de atividades tendem a encorajar maior uso do Setor 2 - Armazéns pelo público em geral. Além disso, a possibilidade de adaptar a área para eventos e para estacionamento de acordo com o fluxo de pessoas na área também parece ser uma alternativa satisfatória para os respondentes $(80,3 \%$ - 57 de 71), o que permite maior flexibilidade de tipos de espaços no Setor 2 - Armazéns. Por outro lado, o número de respondentes que discorda $(45 \%$ - 32 de 71) predomina sobre aqueles que concordam (31\%) com o uso dos armazéns como escritórios. Resultados similares foram obtidos para cada um dos três grupos, não tendo sido encontradas diferenças estatisticamente significativas (teste Mann-Whitney) entre as opiniões de arquitetos e não arquitetos com formação universitária. Em relação às diretrizes do projeto de revitalização para o Setor 3 - Gasômetro, quase a totalidade dos respondentes $(98,6 \%$ - 69 de 70) concorda ou concorda fortemente com a inclusão de atividades culturais e educacionais no Gasômetro, e uma 
parcela próxima da metade $(44,3 \%$ - 31 de 70$)$ concorda com a criação de áreas cobertas de estacionamento. Adicionalmente, percentuais expressivos de respondentes concordam com a possibilidade de criar conexões entre a cidade de Porto Alegre e o Lago Guaíba por meio de uma passarela elevada para pedestres na Avenida João Goulart $(65,7 \%$ - 46 de 70$)$ e de uma praça acima de um túnel nessa avenida (41,4\% - 29 de 70). Ainda, é muito maior o número de respondentes que concordam $(47,1 \%$ - 33 de 70$)$ do que os que discordam (21,5\% - 15 de 70) com a destruição de um armazém que foi construído com materiais diferentes dos utilizados nos outros armazéns e que não é tombado pelo patrimônio histórico, com o objetivo de aumentar as áreas de espaço aberto para estimular a realização de atividades recreativas e a interação social entre os usuários. Também predomina claramente o número de respondentes que concordam $(47,2 \%$ - 33 de 70$)$ sobre aqueles que discordam $(30 \%$ - 21 de 70$)$ em enfatizar a relação visual, através de vários pátios ajardinados, entre o interior do shopping center e o Lago Guaíba e a Praça Brigadeiro Sampaio. Por outro lado, prevalece claramente a discordância (50\% - 35 de 70) sobre a concordância (34,3\% - 24 de 70) com a construção de um shopping center no Setor 3 - Gasômetro, mesmo que promova o desenvolvimento de atividades comerciais na área e a atração de maior número de usuários. Todavia, foi encontrada uma diferença estatisticamente significativa (teste de Mann-Whitney, chi $^{2}=5,548$, sig. $=0,037)$ entre as opiniões de arquitetos e de não arquitetos com formação universitária; enquanto é muito maior o número de arquitetos que discordam $(62,5 \%)$ do que os que concordam (25\%), é maior o número de não arquitetos com formação universitária que concordam $(46,6 \%)$ do que os que discordam $(33,3 \%)$ com a construção de um shopping center no Setor 3.

\section{Conclusões}

O Cais Mauá é utilizado pela grande maioria do total de respondentes, assim como pela expressiva maioria dos arquitetos, não arquitetos com formação universitária e pessoas sem formação universitária. A maioria do total dos respondentes, assim como a maior parte em cada um dos três grupos, usa o Setor 2 - Armazéns e o Setor 3 Gasômetro, mas não utiliza o Setor 1 - Docas. Por outro lado, o Setor 2 e o Setor 3 são utilizados pela maioria dos respondentes cerca de quatro vezes por ano, o que revela uma pequena frequência de uso desses dois setores. As principais razões para a pequena porcentagem de respondentes que utilizam o Setor 1 - Docas são: passeios de barco; contemplação da paisagem; e participação em atividades culturais. As principais razões para os respondentes utilizarem o Setor 2 - Armazéns são: participação em atividades culturais; contemplação da paisagem; e passeios turísticos no Barco Cisne Branco. As principais razões para os respondentes utilizarem o Setor 3 - Gasômetro são: contemplação da paisagem; participação em atividades culturais; passeios de barco; e prática de esportes. Portanto, as principais razões para os respondentes utilizarem os três setores do Cais Mauá são: participação em atividades culturais; contemplação da paisagem; passeios de barco; e prática de esportes.

Um percentual expressivo dos respondentes está insatisfeito com o uso privado e o acesso restrito ao Setor 1 - Docas, e os arquitetos tendem a ser mais críticos que os não arquitetos com formação universitária em relação a esses aspectos. Esses resultados remetem à importância da inclusão de atividades de usos públicos nos projetos de revitalização de áreas portuárias desativadas, o que possibilita criar conexões entre essas áreas e o restante da cidade (ROBERTSON, 1995), conforme tem sido feito em revitalizações de diversas áreas portuárias desativadas, tais como Baltimore e Boston (DEL RIO, 2001; DONOFRIO, 2007). Na Estação das Docas em Belém do Pará, por exemplo, algumas das diretrizes principais do projeto estavam relacionadas ao uso público do espaço por meio da revitalização dos armazéns do porto para usos mistos (p. ex., bares, restaurantes, equipamentos culturais), e da infraestrutura destinada aos pedestres (p. ex., calçadão com bancos, lixeiras e guarda-corpo) (TOMAZI, 2011). Como no Setor 1 - Docas, aspectos relacionados à privatização do espaço público no Setor 2 - Armazéns são percebidos como inadequados pela maioria dos respondentes. Novamente, arquitetos são mais críticos do que não arquitetos com formação universitária a respeito da avaliação de alguns desses aspectos. Por outro lado, a maioria dos respondentes acha apropriada as atividades culturais realizadas no Setor 2. Diferentemente dos outros dois setores, a maioria dos aspectos no Setor 3 - Gasômetro, nomeadamente usos culturais e de lazer e a prática de esportes, tende a ser avaliada positivamente pela significativa maioria dos respondentes. Entretanto, um número expressivo de respondentes avaliou os aspectos relacionados à infraestrutura do Setor 3 como inadequados, tais como o número reduzido de vagas de estacionamento e a manutenção e limpeza insatisfatórias dos banheiros públicos existentes.

Os aspectos que os respondentes entendem que devem ser melhorados no Cais Mauá estão principalmente relacionados a melhorias na 
infraestrutura local e à promoção de atividades culturais e de lazer, sendo elas: condições de acesso à área; segurança; áreas sombreadas de estar; limpeza e conservação da área; áreas públicas de recreação; caminhos para pedestres e áreas de estacionamento para veículos.

A grande maioria dos respondentes concorda com as seis diretrizes propostas pela Prefeitura de Porto Alegre para a orla, que enfatizam: a facilidade de acesso do pedestre à área e seu uso público; a promoção de atividades relacionada à água; a qualificação e preservação de espaços abertos com vegetação; a otimização de atividades que exploram a conexão visual com o Lago Guaíba; a reciclagem do uso dos armazéns, preservando as edificações existentes; e a promoção de atividades culturais e do turismo local. Especificamente, a preservação de edificações históricas corrobora iniciativas adotadas em outros projetos de revitalização como é o caso da preservação dos armazéns antigos em Granville Island, na cidade de Vancouver, e no Porto Madero, em Buenos Aires (DONOFRIO, 2007; TELLA, 2012), ou do Circuito Histórico e Arqueológico da Celebração da Herança Africana no Porto Maravilha, no Rio de Janeiro, que visa preservar pontos da memória negra na cidade (SILVA; MONIÉ, 2014). Esses aspectos auxiliam na preservação da identidade do lugar, que torna essas áreas atrativas não só para turistas, mas também para a população local, o que possibilita o contato entre diferentes perfis de usuários e auxilia a minimizar a segregação social e o processo de gentrificação que tendem a ocorrer em projetos de revitalização urbana (SANTOS, 1997).

Por outro lado, foram encontradas algumas controvérsias a respeito da diretriz proposta que encoraja a preservação de edifícios existentes na área, sem a construção de novas edificações. Enquanto não arquitetos com formação universitária tendem a se opor à construção de novos edifícios no Cais Mauá, arquitetos tendem a aprovar novas edificações. Os respondentes também tendem a discordar a respeito de três diretrizes propostas que permitem o uso residencial e de escritórios em algumas partes do Cais Mauá e novos edifícios com altura maior que a dos armazéns. Enquanto muito mais arquitetos concordam, um número muito maior de não arquitetos com formação universitária discorda com o uso desses edifícios como escritórios.

Claramente, os respondentes tendem a discordar da diretriz do projeto de revitalização que propõe a construção de três torres (duas para escritórios e uma para hotel) com cem metros de altura no Setor 1 - Docas. Por outro lado, os respondentes concordam em promover atividades culturais na área. Diferentemente do Setor 1 - Docas, a clara maioria dos respondentes concorda com a maioria das diretrizes para o Setor 2 - Armazéns, que encoraja um uso maior desse setor pelo público em geral por meio de atividades relacionadas a lazer, cultura, educação e prática de esportes. Por outro lado, mais respondentes discordam a respeito do uso dos armazéns como escritórios. Por sua vez, a consideração de atividades culturais e educacionais no Gasômetro, a inclusão de áreas cobertas de estacionamentos e o aumento de conexões entre o Cais Mauá e as áreas urbanas adjacentes no projeto de revitalização do Setor 3 - Gasômetro são diretrizes bem vistas pelos respondentes. Eles também tendem a concordar com a destruição de um dos armazéns, não tombado pelo patrimônio histórico e com materiais distintos dos demais armazéns, com o objetivo de aumentar a quantidade de espaço aberto e encorajar a realização de atividades recreacionais e a interação social. Por outro lado, os respondentes em geral tendem a discordar da construção de um shopping center no Setor 3 - Gasômetro. No entanto, enquanto um número maior de arquitetos discorda, um número maior de não arquitetos com formação universitária concorda com a construção do shopping center. Sendo assim, a visão dos respondentes contradiz algumas das diretrizes do projeto de revitalização do Cais Mauá, assim como algumas ideias de projetos de revitalização de orla tal como o da cidade de Edimburgo, com relação à criação de uma área em sua orla com um centro do comércio mundial e com outras atividades comerciais, institucionais e habitacionais (SCHERMER, 2002). Por outro lado, parcerias público-privadas, apesar de possibilitarem a viabilidade de projetos para os quais o poder público não possui recursos suficientes, devem considerar diretrizes que não estejam baseadas apenas em interesses da iniciativa privada (TOMAZI, 2011). A privatização excessiva possibilitada por uma falta de planejamento na região de Cannary Wharf, nas Docklands, em Londres, por exemplo, gerou inúmeras torres comerciais desabitadas e uma desconexão com o restante da cidade (DEL RIO, 2001).

Concluindo, a orla de Porto Alegre, especificamente a área do Cais Mauá, é percebida como importante pelos usuários devido às suas atividades culturais e de lazer com fins públicos, sendo rejeitado o atual uso restrito e privado de algumas partes do Cais Mauá. Apesar de serem encontradas algumas diferenças, arquitetos, não arquitetos com formação universitária e pessoas sem formação universitária têm, em geral, ideias similares a respeito do Cais Mauá. Logo, esses resultados não corroboram aqueles que indicam a

216 Antocheviz, F. B.; Reis, A. T. da L.; Limberger, L. R. L. 
existência de diferenças significativas entre as preferências de arquitetos e leigos (NASAR, 1998). As percepções dos porto-alegrenses se refletem nas avaliações das diretrizes elaboradas pela Prefeitura para a orla e nas diretrizes propostas pela pesquisa, assim como na avaliação do projeto de revitalização da área. Esses resultados são corroborados por aqueles na literatura que indicam que diretrizes voltadas para o uso público dos espaços tendem a ser satisfatórias (MACDONALD, 2008; TELLA, 2012). Portanto, este estudo pode contribuir para um melhor entendimento acerca dos níveis de concordância entre as percepções e a necessidade dos usuários da cidade, as decisões tomadas pelo governo local e as diretrizes de projeto propostas pelos arquitetos para a revitalização do Cais Mauá. Dessa forma, pode também auxiliar na tentativa de reestabelecer as conexões perdidas entre o centro da cidade de Porto Alegre e a orla do Lago Guaíba.

\section{Referências}

B720 FERMÍN VÁZQUEZ ARQUITECTOS. Frente portuário de Porto Alegre, Brasil:

Rehabilitación de los antiguos tinglados + business park + centro comercial + hotel. 2011. Disponível em:

$<$ http://b720.com/es/proyecto/b720_porto_alegre_ brasil_es>. Acesso em: 29 ago. 2012.

BLOG PORTO IMAGEM. Imagens Projeto Cais Mauá. 2011. Disponível em:

$<$ http://portoimagem.wordpress.com/imagens-doprojeto-de-revitalizacao-do-cais-maua/>. Acesso em: 28 ago. 2012.

BROWN, G.; GIFFORD, R. Architects Predict Lay Evaluations of Large Contemporary Buildings: whose conceptual properties? Journal of Environmental Psichology, v. 21, n. 1, p. 9399, 2001.

CASTELLO, L. Percepción Ambiental: Porto Alegre - Rio Guaíba. Ambiente, v. 5, n. 45, p. 7983, 1985.

DEL RIO, V. Voltando as Origens: a revitalização de áreas portuárias nos centros urbanos.

Arquitextos, v. 2, ago. 2001. Disponível em: <http://www.vitruvius.com.br/revistas/read/arquite xtos/02.015/859>. Acesso em: 10 ago. 2015.

DONOFRIO, J. T. Preservation as a Tool for Waterfront Revitalization: design, management, and financing solutions from Vancouver, Boston. Pensilvânia, 2007. Dissertação (Mestrado em Preservação Histórica) Universidade da Pensilvânia, 2007. Disponível em: <http://repository.upenn.edu/hp_theses/72>. Acesso em: 31 set. 2012.
FAWCETT, W. et al. Reconciling the Architectural Preferences of Architects and the Public: the ordered preference model.

Environment and Behavior, v. 40, n. 5, p. 599618, set. 2008.

GOOGLE MAPS. [Mapa]. Disponível em: <https://www.google.com.br/maps/place/PopCente $\mathrm{r} / @-30.0240821,-$

$51.2342115,2735 \mathrm{~m} /$ data $=! 3 \mathrm{~m} 1 ! 1 \mathrm{e} 3 ! 4 \mathrm{~m} 13 ! 1 \mathrm{~m} 7 ! 3 \mathrm{~m}$ 6!1s0x95199cd2566acb1d:0x603111a89f87e91f!2 sPorto+Alegre, +RS!3b1!8m2!3d-30.0346471!4d$51.2176584 ! 3 \mathrm{~m} 4$ ! 1 $\mathrm{s} 0 \times 00: 0 \times 690 \mathrm{a} 135025 \mathrm{cce} 853$ ! $8 \mathrm{~m}$ 2!3d-30.0264273!4d-51.2244603>. Acesso em: 19 out. 2012.

HUFFPOST. Baltimore Harborplace Sold to New York Real State Firm Ashkenazi Aquisition Corp. Disponível em:

<http://www.huffingtonpost.com/2012/10/24/balti more-harborplace-sold_n_2009218.html>. Acesso em: 02 maio 2017.

MACDONALD, E. The Efficacy of Long-Range Physical Planning: the case of Vancouver. Journal of Planning History, v. 7, n. 3, p. 175-213, 2008.

MARSHALL, R. Waterfronts in Post Industrial Cities. London: Spon Press, 2001.

MELENDEZ, A. Jaime Lerner e b720

Arquitectos: Complexo Cais Mauá. Porto Alegre, 2011. Disponível em:

<http://www.arcoweb.com.br/arquitetura/jaimelerner-arquitetos-associados-b720-fermin-vazquezarquitecto-revitalizacao-urbana-13-04-2011.html> . Acesso em: 28 ago. 2012.

NASAR, J. The Evaluative Image of the City. Thousand Oaks, CA: Sage, 1998.

PASSOS, F. P. Entre Cantos, Batuques e Grafias: vivências culturais nos espaços públicos das zonas portuárias do Rio de Janeiro. In: ENCONTRO DA ASSOCIAÇÃO NACIONAL DE PROGRAMAS DE PÓS-GRADUAÇÃO E PESQUISA EM PLANEJAMENTO URBANO, 15., Recife, 2013. Anais... Recife, 2013.

PORTO IMAGEM. Imagens Projeto Cais Mauá. Disponível em: $<$ http://portoimagem.wordpress.com/imagens-doprojeto-de-revitalizacao-do-cais-maua>. Acesso em: 02 maio 2017.

\section{PORTO MARAVILHA. Reinauguração da}

Praça Mauá. Disponível em:

<http://portomaravilha.com.br/fotos_videos/g/26>. Acesso em: 08 maio 2017. 
PREFEITURA MUNICIPAL DE PORTO

ALEGRE. SECRETARIA DO PLANEJAMENTO

MUNICIPAL DE PORTO ALEGRE. A

Reintegração do Guaíba ao Cotidiano da Cena

Urbana. Porto Alegre PMPA, 2010.

PREFEITURA MUNICIPAL DE PORTO

ALEGRE. SECRETARIA DO PLANEJAMENTO MUNICIPAL DE PORTO ALEGRE. Cais Mauá.

Disponível em:

<http://lproweb.procempa.com.br/pmpa/prefpoa/vi vaocentro/default.ph...>. Acesso em: 29 ago. 2012.

PURCELL, A.T.; NASAR, J.L. Experiencing Other People's Houses: a model of similarities and differences in environmental experience. Journal of Environmental Psichology, v. 12, p. 199-211, 1992.

REIS, A. T. et al. Estética Urbana: uma análise através das ideias de ordem, estímulo visual, valor histórico e familiaridade. Ambiente Construído, Porto Alegre, v. 11, n. 4, p.185-204, out./dez. 2011.

ROBERTSON, K. A. Downtown Redevelopment Strategies in the United States. Journal of the American Planning Association, v. 61, n. 4, p. 429-438, 1995.

SANOFF, H. Visual Research Methods in Design. New York: Van Nostrand Reinhold, 1991.

SANTOS, M. A Natureza do Espaço. Tecnica e Tempo. Razão e Emoção. São Paulo: Hucitec, 1997.
SCHERMER, B. On the Waterfront. In: Edinburgh Urban Design Charrette, 32., Philadelphia, 2002. Proceedings... Philadelphia, 2002.

SILVA, V; MONIÉ, F. O Local e o Global no Projeto na Operação Urbanística "Porto Maravilha" - Rio de Janeiro. In: MEGA EVENTOS - CONFERÊNCIA INTERNACIONAL, 2., Rio de Janeiro, 2014. Anais... Rio de Janeiro, 2014.

TELLA, G. Porto Madero: uma transformação urbana em Buenos Aires. Disponível em: $<$ http://lproweb.procempa.com.br/pmpa/prefpoa/ vivaocentro/usu_doc/puertomadero.pdf $>$. Acesso em: 19 out. 2012 .

TOMAZI, V. T. Urbanização Turística Litorânea e Grandes Projetos Urbanos Promovidos Por Investimentos Públicos em Belém (PA) e Fortaleza (CE) entre 1990 e 2010. São Paulo, 2011. Dissertação (Mestrado em Geografia) - Escola de Geografia, Universidade de São Paulo, São Paulo, 2011

TUTIKIAN, E. Projeto Porto - Cais Mauá Horizonte, Perspectivas. 2008. Disponível em: $<$ http://lproweb.procempa.com.br/pmpa/ prefpoa/vivaocentro/usu_doc/caismaua.pdf>. Acesso em: 19 out. 2012.

VIAJAR É SIMPLES. Capitais Brasileiras se Preparam Para o Réveillon. Disponível em: <http://www.viajaresimples.com.br/randomico_ifr ame.php?id=66>. Acesso em: 08 maio 2017.

Fabiana Bugs Antocheviz

Programa de Pós-Graduação em Planejamento Urbano e Regional | Universidade Federal do Rio Grande do Sul | Rua Sarmento Leite, 320 Centro Histórico | Porto Alegre - RS - Brasil | CEP 90050-170 | Tel.: (051) 3308-3124 | E-mail: fabianabugs@hotmail.com

Antônio Tarcísio da Luz Reis

Departamento de Arquitetura, Faculdade de Arquitetura | Universidade Federal do Rio Grande do Sul | Tel.: (51) 3316-3152 |

E-mail: tarcisio.reis@ufrgs.br

\section{Lucienne Rossi Lopes Limberger}

Departamento de Arquitetura e Urbanismo, Centro de Tecnologia | Universidade Federal de Santa Maria | Av. Roraima, Prédio 30, Sala 214, Camobi | Santa Maria - RS - Brasil | CEP 97105-900 | Tel.: (55) 3220-8771 | E-mail: lulimbe@gmail.com

\section{Revista Ambiente Construído}

Associação Nacional de Tecnologia do Ambiente Construído

Av. Osvaldo Aranha, $99-3^{\circ}$ andar, Centro

Porto Alegre - RS - Brasil CEP 90035-190

Telefone: +55 (51) 3308-4084

Fax: +55 (51) 3308-4054

www.seer.ufrgs.br/ambienteconstruido

E-mail: ambienteconstruido@ufrgs.br 